\section{A) Check for updates}

Cite this: Dalton Trans., 2019, 48, 4894

Received 21st December 2018, Accepted 28th February 2019

DOI: $10.1039 / \mathrm{c} 8 \mathrm{dt} 05051 \mathrm{a}$ rsc.li/dalton

\title{
Applications of boroxide ligands in supporting small molecule activation by U(III) and U(Iv) complexes $\uparrow$
}

\author{
Polly L. Arnold, (D)*a Laura Puig-Urrea, ${ }^{a}$ Jordann A. L. Wells, (D) $t^{a}{ }^{a}$ Dan Yuan, (D) ${ }^{b}$ \\ Faye L. Cruickshank ${ }^{a}$ and Rowan D. Young (D) ${ }^{a}$
}

\begin{abstract}
The boroxide ligand $\left[\mathrm{OBAr}_{2}\right]^{-}\left(\mathrm{Ar}=\mathrm{Mes}\right.$, Trip) is shown to be able to support both $\mathrm{U}^{\mathrm{III}}$ and $\mathrm{U}^{\mathrm{IV}}$ centres for the first time. The synthesis and structures of homoleptic and heteroleptic $U^{\prime \prime \prime}$ and $U^{\prime V}$ complexes are reported. The $U_{3}$ complex with larger substituents, $\left[U(\mathrm{OBTrip})_{3}\right]_{2}$, exhibits greater thermal stability compared to less encumbered $\left[\mathrm{U}(\mathrm{OBMes})_{3}\right]_{2}$ but reacts with a smaller range of the small molecules tested to date. Initial studies on their capacity to participate in small molecule chemistry show that dark purple $\left[\mathrm{U}(\mathrm{OBMes})_{3}\right]_{2}$ binds and/or reductively activates a variety of small molecules such as pyridineoxide, triphenylphosphineoxide, sulfur, and dicyclohexylcarbodiimide. While $\left[\mathrm{U}\left(\mathrm{OBMes}_{2}\right)_{3}\right]_{2}$ shows no reaction with $\mathrm{CO}$ or $\mathrm{CO}_{2}$, [U(OBTrip $\left.)_{3}\right]_{2}$ is oxidised by both, in the former case forming [U $\left.(\mathrm{OBTrip})_{4}\right]$, and in the latter case forming a small quantity of the structurally characterised $\mu$-carbonate product $\left[\left(\mu-\mathrm{CO}_{3}\right)\left\{\mathrm{U}(\mathrm{OBTrip})_{3}\right\}_{2}\right]$.
\end{abstract}

\section{Introduction}

Complexes of the form $\mathrm{UX}_{3}$ where $\mathrm{X}$ is a large, monoanionic ligand such as an amide or aryloxide have shown great utility in the binding and reductive activation of small molecules. The choice of $\mathrm{X}$ provides great control over the space at the Lewis acidic metal, and the strength of the reducing capacity of the $\mathrm{U}^{\mathrm{III}}$ centre. For example, the common silylamide and aryloxide complexes $\left[\mathrm{UN}_{3}{ }_{3}\right]$ and $\left[\mathrm{U}(\mathrm{ODtbp})_{3}\right]\left(\mathrm{N}^{\prime \prime}=\mathrm{N}\left(\mathrm{SiMe}_{3}\right)_{2}\right.$, ODtbp $=$ O-2,6- ${ }^{t} \mathrm{Bu}_{2} \mathrm{C}_{6} \mathrm{H}_{3}$ ) reductively couple carbon monoxide gas at room temperature and pressure to form the $[\mathrm{OCCO}]^{2-}$ fragment as the sole product in $\left[\mathrm{X}_{2} \mathrm{UOCCOUX}_{2}\right] \cdot{ }^{1,2}$ The dinuclear tren derivative $\left[\left\{\mathrm{U}\left(\operatorname{tren}^{\prime}\right)\right\}_{2}\left(\mu-\eta^{2}: \eta^{2}-\mathrm{N}_{2}\right)\right]$ (tren' $=$ $\left.\mathrm{N}\left(\mathrm{NCH}_{2} \mathrm{CH}_{2} \mathrm{NSi}^{t} \mathrm{BuMe}_{2}\right)_{3}\right)$ and $\left[\mathrm{U}(\mathrm{ODtbp})_{3}\right]$ show ready but reversible side-on $\mathrm{N}_{2}$ coordination, ${ }^{2}$ but the OTtbp analogue $\left(\mathrm{OTtbp}=\mathrm{O}-2,4,6{ }^{t}{ }^{\mathrm{B}} \mathrm{Bu}_{3} \mathrm{C}_{6} \mathrm{H}_{2}\right)\left[\left\{\mathrm{U}(\mathrm{OTtbp})_{3}\right\}_{2}\left(\mu-\eta^{2}: \eta^{2}-\mathrm{N}_{2}\right)\right]$ releases

\footnotetext{
${ }^{a}$ EaStCHEM School of Chemistry, Joseph Black Building, The King's Buildings, The University of Edinburgh, Edinburgh, EH9 3FJ, UK

${ }^{b}$ Key Laboratory of Organic Synthesis of Jiangsu Province, College of Chemistry, Chemical Engineering and Materials Science, Soochow University, Dushu Lake Campus, Suzhou 215123, People's Republic of China

$\dagger$ Electronic supplementary information (ESI) available: General experimental considerations, preparation of reagents and additional experimental details. CCDC 1886802-1886811, 1886182 and 1886183 (complex $\mathbf{1 1}^{\mathrm{t}}$ and $2^{\mathrm{t}}$ ). For ESI and crystallographic data in CIF or other electronic format see DOI: 10.1039/c8dt05051a \$Current address. Department of Chemistry, Ångström Laboratory, Uppsala University, Uppsala, Sweden.
}

$\mathrm{N}_{2}$ only upon heating a solution to $80^{\circ} \mathrm{C}$, even in the presence of small O-containing reagents such as $\mathrm{CO}_{2}$ and $\mathrm{CO}^{2}$

We showed that bulky trimesitylsiloxide complexes bind $\mathrm{N}_{2}$ even more strongly in $\left[\left\{\mathrm{U}\left(\mathrm{OSiMes}_{3}\right)_{3}\right\}_{2}\left(\mu-\eta^{2}: \eta^{2}-\mathrm{N}_{2}\right)\right],{ }^{3}$ and others have shown that further functionalisation of the trapped and reduced $\mathrm{N}_{2}$ in polymetallic nitrido complexes supported by tertbutylsiloxides is possible. ${ }^{4}$ Flexible uranium siloxides have also allowed reactions such as $\mathrm{CO}_{2}$ deoxygenation and carbonate formation in $\left[\left\{\mathrm{U}\left(\mathrm{OSi}\left(\mathrm{O}^{t} \mathrm{Bu}\right)_{3}\right)_{3}\right\}_{2}\left(\mu-\eta^{1}: \eta^{2} \mathrm{CO}_{3}\right)\right] .^{5}$

The capacity to transfer one $\mathrm{X}$ ligand has also provided significant advantages for new reactivity. For example, storage of arene solutions of $\left[\mathrm{UX}_{3}\right]\left(\mathrm{X}=\mathrm{N}^{\prime \prime}\right.$, ODtbp) results in the spontaneous reductive activation of the arene (over $90 \mathrm{~h}$ at $90{ }^{\circ} \mathrm{C}$, or 30 days at $\left.25{ }^{\circ} \mathrm{C}\right)$ through the formation of $\left[\left\{\mathrm{X}_{2} U\right\}_{2}\left(\mu-\eta^{6}: \eta^{6}-\right.\right.$ $\left.\mathrm{C}_{6} \mathrm{H}_{6}\right)$ ] and elimination of two equivalents of $\mathrm{UX}_{4}$ by-product. ${ }^{6}$ The trapped arenes are also sufficiently reduced that a mild, homogeneous borylation of one $\mathrm{C}-\mathrm{H}$ group is possible.

Boroxides provide an interesting alternative to alkoxides and aryloxides as these can provide greater delocalisation of the electron density across the OBM bond, and even a distant Lewis acidity via an empty orbital on the boron atom, thus allowing the electron density to be tuned at the metal centre. ${ }^{7}$ The aryl functionalisation can also provide a larger protected pocket at the metal as the bulk of the aryl groups is maintained at a greater distance from the metal binding site. ${ }^{8}$

We have studied the capacity of the boroxide ligand $\left[\mathrm{OBAr}_{2}\right]^{-}\left(\mathrm{Ar}=\right.$ Mes, Trip) to bind $\mathrm{U}^{\mathrm{III}}$ for the first time. Here we show the synthesis and structures of new $\mathrm{U}^{\mathrm{III}}$ and $\mathrm{U}^{\mathrm{IV}}$ com- 
plexes and initial studies on their capacity to participate in small molecule chemistry.

\section{Results and discussion}

\section{Syntheses}

The formation of dark purple $\left[\mathrm{U}\left(\mathrm{OBMes}_{2}\right)_{3}\right]_{2} \quad \mathbf{1}^{\mathbf{m}}$ from $\mathrm{HOBMes}_{2}$ and $\mathrm{UN}^{\prime}{ }_{3}$ occurs in less than 3 hours at room temperature in toluene solution, Scheme 1. Work-up from hexanes affords dark crystals in $46 \%$ yield, suitable for a single crystal X-ray diffraction study, Fig. 1 . At room temperature the ${ }^{1} \mathrm{H}$ NMR spectrum of 1 shows the retention of the dimeric structure in solution with two different sets of ligand resonances assignable to terminal and bridging ligands. The bulkier aryl groups on the boroxide still lead to similar reaction chemistry to afford $\left[\mathrm{U}\left(\mathrm{OBTrip}_{2}\right)_{3}\right]_{2} \mathbf{1}^{\mathbf{t}}$, although the major by-product in the synthesis is the tetrakis(ligand) complex $2^{\mathrm{t}}$, and both $\mathrm{UX}_{3}$ and $\mathrm{UX}_{4}$ are isolated by fractional crystallisation in similar ( $c a$. $30 \%$ ) yields. The disproportionation of uranium(III) to uranium(Iv) and uranium metal is a known oxidative pathway. ${ }^{6,9,10}$ Dark red crystals of the mononuclear diethylether adduct $\left[\left(\mathrm{Et}_{2} \mathrm{O}\right) \mathrm{U}\right.$ $\left.\left(\text { OBTrip }_{2}\right)_{3}\right] \mathbf{1}^{\mathbf{t}}-\mathbf{E t}_{\mathbf{2}} \mathbf{O}$ are formed from reactions in diethyl ether and have also been structurally characterised by a single crystal X-ray diffraction study, Fig. 1 . The ${ }^{1} \mathrm{H}$ NMR spectrum of $\mathbf{1}^{\mathbf{m}}$ suggests exchange between unbound and bound Ar groups on bridging $\mathrm{OBMes}_{2}$ at ambient temperature and support the dimeric conformation. The resonances assigned to the bridging ligands are strongly paramagnetically shifted out of the diamagnetic region (from -3.71 to $-15.13 \mathrm{ppm}$ ) due to proximity to the uranium centres, whereas the resonances corresponding to the terminal ligands (double the relative intensity) are between 8.29 to $2.53 \mathrm{ppm}$. The ${ }^{11} \mathrm{~B}$ NMR spectrum contains a resonance at $73.7 \mathrm{ppm}$ that is tentatively assigned to one of

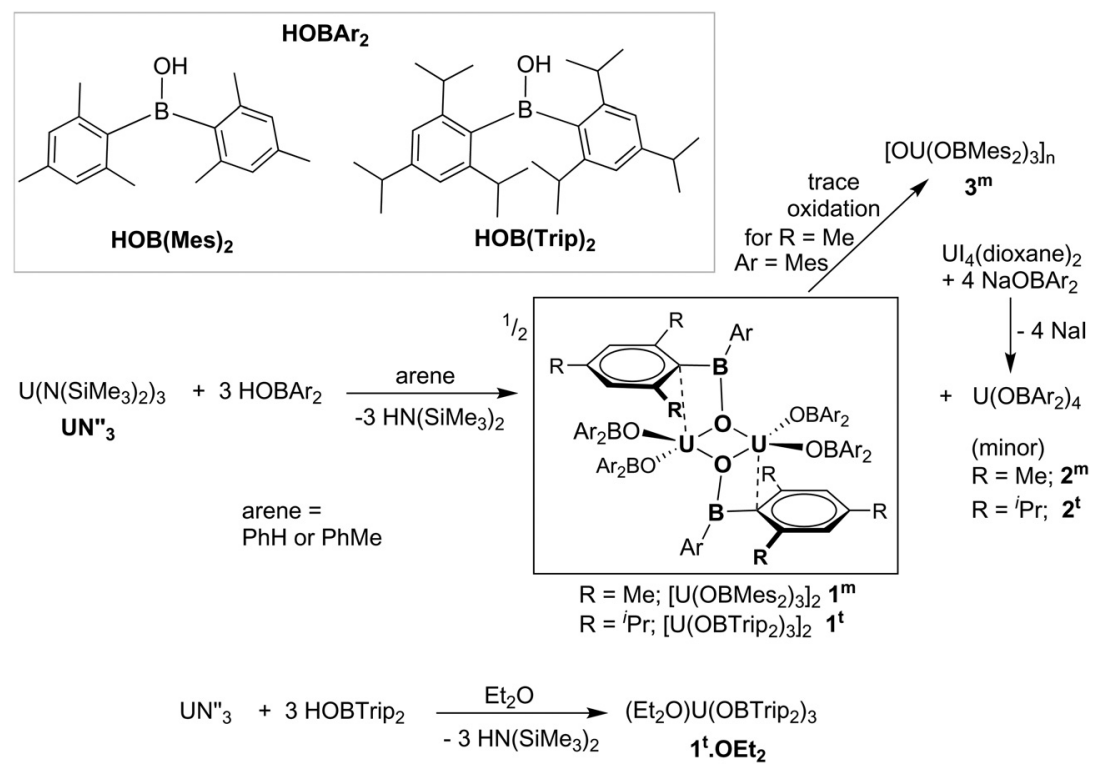

Scheme 1 Synthesis of complexes 1 showing common by-products and decomposition products.

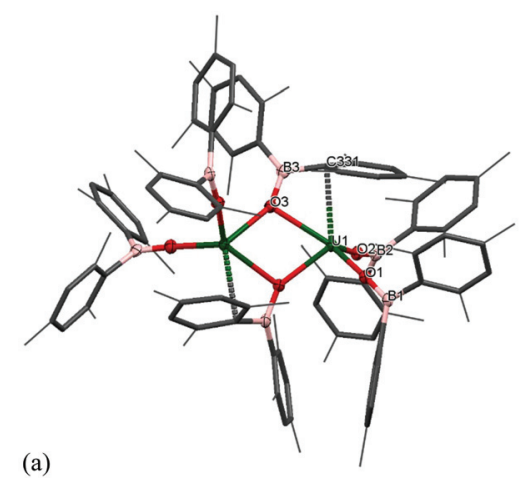

(a)

Fig. 1 Displacement ellipsoid drawing of the molecular structure of (a) $1^{\mathrm{m}}$ and (b) $1^{\mathrm{t}}-\mathrm{Et}_{2} \mathrm{O}$. The hydrogen atoms are omitted and the mesityl and triisopropylphenyl groups are depicted as wireframe and capped sticks for clarity. The thermal ellipsoids are displayed at $50 \%$ probability. 
what should be two different boron environments, but only one other signal attributed to trace free ligand $(50.8 \mathrm{ppm})$ is observed over an extended frequency range.

Clean starting materials and precise control of the stoichiometry is key to the formation of pure samples, as both derivatives of $\mathbf{1}$ are very air sensitive. The homoleptic $\mathrm{U}^{\mathrm{IV}}$ complexes $\left[\mathrm{U}\left(\mathrm{OBAr}_{2}\right)_{4}\right] 2$ are significantly more stable, and can be formed as minor side products in syntheses of $\mathbf{1}$, and from independent metathetical routes from the reaction between uranium tetraiodide and the salt $\mathrm{NaOBAr}_{2}$, Scheme 1. A high-yielding route to $2^{\mathbf{m}}$ is available from the reaction of $\mathrm{NaOBMes}_{2}$ with $\left[\mathrm{UI}_{4}(1,4 \text {-dioxane })_{2}\right]$ in toluene, affording $\left[\mathrm{U}\left(\mathrm{OBMes}_{2}\right)_{4}\right.$ (dioxane $\left.)_{0.5}\right]_{2}\left(2^{\mathbf{m}} \cdot\right.$ diox $)$. Colourless crystals of $2^{\mathbf{m}} \cdot$ diox and $2^{\mathbf{t}} \cdot \mathbf{C}_{7} \mathbf{H}_{\mathbf{8}}$ suitable for XRD analysis were obtained from slow diffusion of hexanes into the reaction mixture, and standing of a concentrated toluene solution, respectively, see below. Complex $2^{\mathbf{m}} \cdot$ diox was characterised by ${ }^{1} \mathrm{H}$ NMR spectroscopy, mass spectrometry (APPI-MS) and single crystal XRD analysis. The ${ }^{1} \mathrm{H}$ NMR spectrum show the corresponding signals of one boroxide ligand environment. Mass spectrometric analysis showed the molecular ion at $m / z=1298.76$ that corresponds to $[\mathrm{M}]^{\bullet+}$ fragment $\left[\mathrm{U}\left(\mathrm{OBMes}_{2}\right)_{4}\right]^{\bullet+}$. The ${ }^{1} \mathrm{H}$ NMR spectrum of $2^{\mathbf{t}}$ contains many more resonances than that of $\mathbf{1}^{\mathbf{t}}$ due to the congestion around metal centre; twelve magnetically different methyl group resonances are measured in the range of 4.13-18.40 ppm and five different methine groups are discernible in the range $8.86-4.78 \mathrm{ppm}$.

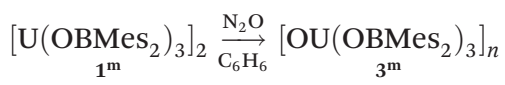

Additionally, complex $\mathbf{1}^{\mathbf{m}}$ is readily oxidised to the oxo $\mathrm{U}^{\mathrm{IV}}$ product $\left[\mathrm{OU}\left(\mathrm{OBMes}_{2}\right)_{3}\right]_{n} 3^{\mathbf{m}}$, due to the presence of traces of oxygen, which has been fully characterised from an independent synthesis. Samples also decompose when heated to $100{ }^{\circ} \mathrm{C}$ in toluene or in the solid state $\left(10^{-3}\right.$ mbar, $\left.115^{\circ} \mathrm{C}, 6 \mathrm{~h}\right)$. Upon exposure of a benzene solution of complex $\mathbf{1}^{\mathbf{m}}$ to one atmosphere of dry $\mathrm{N}_{2} \mathrm{O}$, a rapid colour change from dark purple to light brown is observed due to the formation of the $\mathrm{U}^{\mathrm{IV}}$ oxo complex $3^{\mathbf{m}}$, which is assigned as containing bridging oxo ligands by comparison with the literature and in consideration of the size of the $\mathrm{OBMes}_{2}$ ligands, eqn (1). The ${ }^{1} \mathrm{H}$ and ${ }^{13} \mathrm{C}$ NMR spectra show resonances corresponding to one mesityl environment, which is slightly shifted due to paramagnetic contributions. The ${ }^{11} \mathrm{~B}$ NMR spectrum contains one resonance at $89.29 \mathrm{ppm}$, which confirms the presence of only one boron environment. The elemental analysis result is in agreement with the formation of $3^{\mathbf{m}}$. Reactions designed to reduce complex $3^{\mathbf{m}}$ on a bulk scale have so far been unsuccessful; a small quantity of a $\mathrm{U}^{\mathrm{III}}$ product $\mathrm{K}_{2}\left[\left\{\left(\mathrm{OBMes}_{2}\right)_{3} \mathrm{U}_{2}(\mu-\mathrm{O})_{2}\right]\left(\mathbf{1 0}^{\mathbf{m}}\right)\right.$ that was isolated from a reaction with $\mathrm{KC}_{8}$ has been structurally characterised (see ESI $\dagger$ for details).

Any traces of the metallacycle $\left[\mathrm{UN}_{2}^{\prime \prime}\left\{\mathrm{\kappa}^{2}-\mathrm{N}^{\prime}\left(\mathrm{SiMe}_{2} \mathrm{CH}_{2}\right)\right\}\right]\left(\mathrm{N}^{\prime}=\right.$ $\mathrm{N}\left(\mathrm{SiMe}_{3}\right)$, a common $\mathrm{U}^{\mathrm{IV}}$ contaminant in $\mathrm{UN}_{3}{ }_{3}$, forms $\left[\mathrm{UN}_{3}\left(\mathrm{OBMes}_{2}\right)\right]$ and $\left[\mathrm{UN}_{3}\left(\mathrm{OBTrip}_{2}\right)\right]$ (vide infra).

\section{Crystallography}

The solid-state structure of $\mathbf{1}^{\mathbf{m}}$ confirms the formation of a centrosymmetric binuclear $\mathrm{U}^{\mathrm{III}}$ complex in which the two uranium centres are bridged by two boroxide ligands (Fig. 1a) in a distorted trigonal bipyramid geometry due to the interaction of the uranium centres with the bridging mesityl groups. The $\mathrm{U} \cdots \mathrm{C}$ distances for these interactions $\left(\mathrm{U} \cdots \mathrm{C}_{\mathrm{avg}}\right.$ $2.845 \AA$ ) are slightly longer than other $\eta^{1}$ interactions with uranium, such as the complexes bearing the ligand $\{1,3[2,5$ $\left.\left.\left({ }^{\mathrm{i}} \mathrm{Pr}\right)_{2} \mathrm{PhNC}\left(=\mathrm{CH}_{2}\right)\right] \mathrm{C}_{6} \mathrm{H}_{4}\right\}$ reported by Gambarotta and coworkers $(2.678(12) \AA) .{ }^{11}$ The U-O bond lengths for the boroxide ligands are 2.548(10) $\AA$ and 2.372(10) $\AA$ for the bridging boroxides, and an average $\mathrm{U}-\mathrm{O}_{\text {avg }}$ bond length of $2.196 \AA$ for the terminal boroxides. Both are in the same range as the U-O distances for the siloxide-bridged $\mathrm{U}^{\mathrm{III}}$ dimer reported by Mazzanti and co-workers, $\left[\mathrm{U}\left(\mathrm{OSi}\left(\mathrm{O}^{t} \mathrm{Bu}\right)_{3}\right)_{2}\left(\mu-\mathrm{OSi}\left(\mathrm{O}^{t} \mathrm{Bu}\right)_{3}\right)\right]_{2}$, which features two $\mathrm{U}^{\mathrm{III}}$ centres with two bridging and two terminal siloxide ligands with U-O distances of 2.549(3) Å and 2.396(3) Å for the bridging siloxides, and a U- $\mathrm{O}_{\text {avg }}$ of 2.193(4) $\AA$ for the terminal ligands. Moreover, the $\mathrm{U} \cdots \mathrm{U}$ distance for complex $\mathbf{1}^{\mathbf{m}}$ is $3.966 \AA$, which is similar to the $\mathrm{U}^{\mathrm{III}}$ siloxide complex (U... 3.9862(2) ̊). ${ }^{5}$ The $\mathrm{U}-\mathrm{O}_{\text {avg }}$ distance for the terminal ligands is similar to that of $\left[\left(\mathrm{Et}_{2} \mathrm{O}\right) \mathrm{U}\left(\mathrm{OBTrip}_{2}\right)_{3}\right] \mathbf{1}^{\mathbf{t}}-\mathbf{E t}_{2} \mathbf{O}$ (mean 2.183(7) $\mathrm{A}$ ) and slightly longer than that of the uranium tris(aryloxide) complex, $\left[\mathrm{U}(\mathrm{ODtbp})_{3}\right]$, with $\mathrm{U}-\mathrm{O}_{\text {avg }}=2.159 \AA$. The average $\mathrm{B}-\mathrm{O}$ bond length of complex $\mathbf{1}^{\mathbf{m}}$ is $1.351 \AA$. For both complexes the $\mathrm{B}-\mathrm{O}_{\mathrm{avg}}$ fall within range for $\mathrm{Ar}_{2} \mathrm{BO}-\mathrm{M}$ complexes reported in the literature (1.295-1.405 $\AA$, mean 1.350(1) $\AA$ for a fragment search for $\mathrm{Mes}_{2} \mathrm{BO}-\mathrm{M}$ in the Cambridge Structural Database). ${ }^{12}$ In the solid-state structure of $\mathbf{1}^{\mathbf{t}}-\mathbf{E t}_{\mathbf{2}} \mathbf{O}$ the average $\mathrm{U}-\mathrm{O}_{\text {boroxide }}$ distance is $2.183 \AA$, slightly shorter in $\mathbf{1}^{\mathbf{m}}$ but significantly longer than in $\left[\mathrm{U}(\mathrm{ODtbp})_{3}\right](2.159 \AA)$. The $\mathrm{U}-\mathrm{O}_{\text {ether }}$ is $2.530(7) \AA$ and is much shorter than in the seven-coordinate complex $\left[\left\{\left({ }^{\mathrm{Neop}} \mathrm{ArO}\right)_{3} \operatorname{tacn}\right\} \mathrm{U}\left(\mathrm{OEt}_{2}\right)\right]$ (2.669(2) $\AA$, ${ }^{\mathrm{Neop}} \mathrm{ArO}=$ 2-neopentyl4-methylphenoxide, tacn = triazacyclononane), which is the only other crystallographically characterised $\mathrm{U}^{\mathrm{III}}$ diethyletherate. ${ }^{13}$ This is consistent with both the more electrondeficient uranium centre engendered by the poor $\pi$ donor properties of the boroxide ligand and the lower coordination number in $\mathbf{1}^{\mathbf{t}}-\mathbf{E t}_{\mathbf{2}} \mathbf{O}$.

Together, the nearly linear $\mathrm{U}-\mathrm{O}-\mathrm{B}$ angle for the terminal boroxide ligands (mean $171.6^{\circ}$ in $\mathbf{1}^{\mathbf{m}} 171.0^{\circ}$ in $\mathbf{1}^{\mathbf{t}}-\mathbf{E t}_{2} \mathbf{O}$ ) and the elongation of the $\mathrm{U}-\mathrm{O}$ bonds are a direct consequence of the reduced $\pi$-donor ability of the ligand compared with a carbocyclic aryloxide, which is decreased by having a boron substituent on the ligand. Electron density from the oxygen is accepted by the boron, leading to a lower degree of $\pi$-donation from the boroxide to the uranium centre.

The solid-state structure of $2^{\mathbf{m}} \cdot$ diox reveals two $\mathrm{U}^{\mathrm{IV}}$ ions both in a distorted trigonal bipyramidal coordination environment (Fig. 2a). Each uranium centre is ligated by one end of a bridging dioxane molecule in an axial position with a $\mathrm{U}-\mathrm{O}$ distance of $2.577(3) \AA$, which is considerably longer than in $\left[\mathrm{UI}_{4}(1,4\right.$ dioxane $\left.)_{2}\right]$ or the $\left[\mathrm{UI}_{2} \text { (dioxane }\right)_{2}$ (aryloxide)] previously reported by our group $\left(\right.$ mean $=2.333(6) \AA$ and $2.087 \AA$ respectively). ${ }^{14-16}$ The 

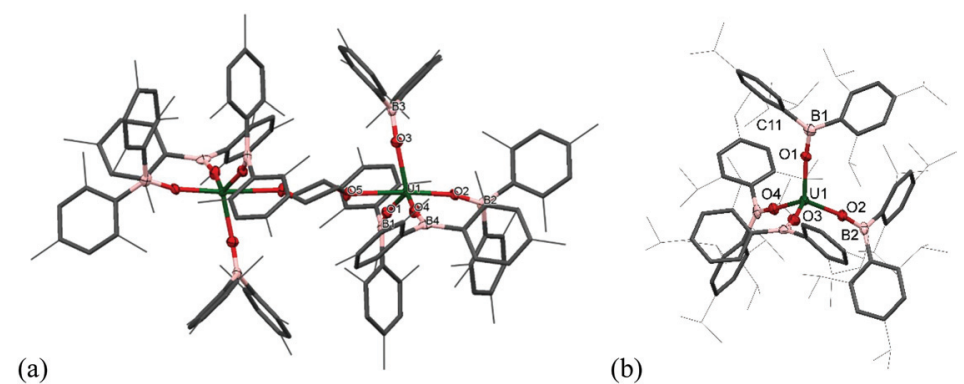

(b)

Fig. 2 Displacement ellipsoid drawing of the molecular structure of (a) $2^{\mathrm{m}} \cdot$ diox and (b) $2^{\mathrm{t}} \cdot \mathrm{C}_{7} \mathrm{H}_{8}$. Thermal ellipsoids are displayed at $50 \%$ probability. Lattice solvent and hydrogen atoms omitted, and aryl substituents are depicted as wireframe and capped sticks for clarity.

boroxide ligands in the equatorial positions have a $\mathrm{U}-\mathrm{O}_{\text {avg }}$ distance of 2.144(3) $\AA$, which is shorter than in the uranium(III) complex $\mathbf{1}^{\mathbf{m}}$, consistent with a $\mathrm{U}^{\mathrm{IV}}$ centre, and similar to the $\mathrm{U}-\mathrm{O}$ bond length for $\left[\mathrm{U}(\mathrm{OBTrip})_{4}\right]$ with a U-O distance of 2.159(5) A. The boroxide ligands in the axial positions have a $\mathrm{U}-\mathrm{O}$ distance of 2.095(3) $\AA$, which is much shorter than the equatorial boroxides. The $\mathrm{B}-\mathrm{O}_{\text {avg }}$ distance is $1.356 \AA$, which is similar to complex $\mathbf{1}^{\mathrm{m}}$ and falls within range for reported metal boroxide complexes. The U-O- $\mathrm{B}_{\text {avg }}$ angles are $167.1^{\circ}$, which is comparable to the U-O$\mathrm{B}$ angles of the terminal boroxide ligands in $\mathbf{1}^{\mathrm{m}}$ (mean $171.6^{\circ}$ ).

Single crystals of $2^{\mathrm{t}} \cdot \mathrm{C}_{7} \mathrm{H}_{8}$ suitable for X-ray diffraction analysis were obtained from concentrated toluene solution, and its solid-state structure is depicted in Fig. 2b. The solid-state structure shows an unsolvated four-coordinate uranium centre in tetrahedral geometry. The mean boroxide ligand $\mathrm{U}-\mathrm{O}$ distance of 2.159(5) $\AA$ is shorter than in the uranium(III) complex $\mathbf{1}^{\mathbf{t}}-\mathbf{E t}_{2} \mathbf{O}$, consistent with a uranium(Iv) centre. The U-O bond lengths in $2^{\mathbf{t}}$ are longer than those in homoleptic uranium(IV) aryloxide [U(ODtbp $\left.)_{4}\right](2.135(4) \AA)$, due to the greater steric demand of the boroxide ligand and poorer metal to ligand backbonding. The U-O-B angles are comparable to those in $\mathbf{1}^{\mathbf{t}}-\mathbf{E t}_{2} \mathbf{O}$ (mean $171.0(5)^{\circ}$ ), despite the considerable bulk about the uranium centre. The average B-O bond length of 1.364(7) $\AA$ falls within range for reported metal boroxide complexes and is slightly longer than in $\mathbf{1}^{\mathbf{t}}-\mathbf{E t}_{\mathbf{2}} \mathbf{O}$. The longer $\mathrm{B}-\mathrm{O}$ bond may be due to the more Lewis acidic uranium(rv) centre in $2^{\mathrm{t}}$.

\section{Reactions of $1^{\mathrm{m}}$ and $1^{\mathrm{t}}$}

Compound $\mathbf{1}^{\mathbf{m}}$ has been treated with a wide range of small molecules, Scheme 2.

Reactions with small, neutral N- or P-donor reagents that are readily visible by NMR spectroscopy were designed to identify whether the boron atoms in the ligands retain sufficient Lewis acidic character to participate in reactions. However, arene solutions of $\mathbf{1}^{\mathbf{m}}$ showed no reaction with added $\mathrm{Me}_{3} \mathrm{SiN}_{3}, \mathrm{PPh}_{3}, \mathrm{CH}_{2}\left(\mathrm{PPh}_{2}\right)_{2}$ (dppm), $\mathrm{C}_{2} \mathrm{H}_{4}\left(\mathrm{PPh}_{2}\right)_{2}$ (dppe) or white phosphorus, $\mathrm{P}_{4}$. Normal, simple $\mathrm{UX}_{3}$ complexes with large monoanionic $\mathrm{X}$ ligands would be anticipated to react with these, readily forming oxidised uranium complexes or adducts, for example, $\left[\mathrm{Me}_{3} \mathrm{SiN}=\mathrm{UN}_{3}{ }_{3}\right],{ }^{17,18}\left[\mathrm{Me}_{3} \mathrm{SiN}=\mathrm{U}\{\mathrm{OSi}\right.$ $\left.\left.\left(\mathrm{O}^{t} \mathrm{Bu}\right)_{3}\right\}_{3}\right],{ }^{19}\left[\mathrm{U}\left(\mathrm{BH}_{4}\right)_{3}\left(\mathrm{PEt}_{3}\right)_{2}\right] .{ }^{20}$

\section{Pyridine $N$-oxide}

The formation of oxo complexes with structures such as $\mathrm{UL}_{n}=\mathrm{O},{ }^{21-23} \mathrm{~L}_{n} \mathrm{U} \equiv \mathrm{O}^{13,24}$ or $\mathrm{U}-\mathrm{O}-\mathrm{U}^{25}$ have been reported from reactions with pyridine $\mathrm{N}$-oxide. In this case, addition of benzene to a mixture of $\left[\mathrm{U}\left(\mathrm{OBMes}_{2}\right)_{3}\right]_{2}$ and an excess of pyridine $\mathrm{N}$-oxide provides a brown solution from which $\left[\mathrm{U}\left(\mathrm{OBMes}_{2}\right)_{4}(\text { py-O })_{2}\right]\left(4^{\mathrm{m}}\right)$ can be isolated as dark orange solids after 72 hours, Scheme 2. The reaction proceeds through oxidation of complex $\mathbf{1}^{\mathbf{m}}$ to mononuclear $\mathrm{U}^{\mathrm{IV}}$ complex $4^{\mathrm{m}}$ with ligand redistribution. Coordination of pyridine

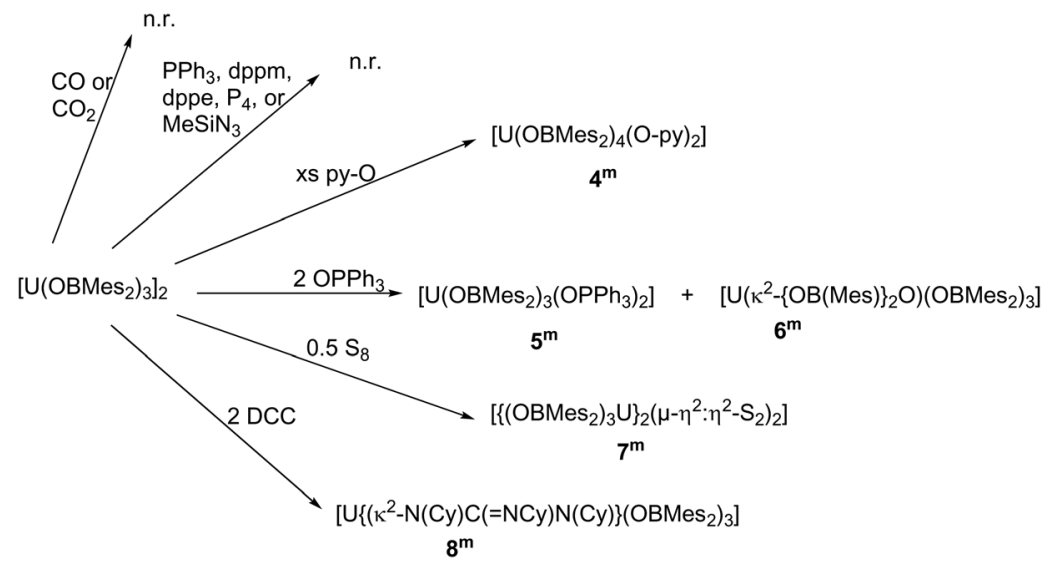

Scheme 2 Reactions of complex $1^{\mathrm{m}}$ investigated. 
$N$-oxide to a metal is not unique, although relatively rare. ${ }^{13,26-29}$ The identity of complex $4^{\mathbf{m}}$ was confirmed by ${ }^{1} \mathrm{H}$ NMR spectroscopy, APPI mass spectrometry and single crystal XRD analysis. Mass spectrometric data showed the expected molecular ion at $m / z=1223.65$, which corresponds to the $[\mathrm{M}]^{\cdot+}$ fragment, $\left[\mathrm{U}\left(\mathrm{OBMes}_{2}\right)_{4}(\mathrm{Py}-\mathrm{O})_{2}\right]^{\bullet+}$. Dark orange crystals of $\mathbf{4}^{\mathbf{m}}$ suitable for XRD analysis were grown from a concentrated benzene solution. The data are of sufficient quality to discuss connectivity information but not for bond metrics. The solid-state structure reveals a $\mathrm{U}^{\mathrm{IV}}$ complex with a distorted octahedral geometry with the boroxide ligands in the equatorial positions and the pyridine $\mathrm{N}$-oxide ligands in the axial positions (Fig. 3).

\section{Triphenylphosphine oxide}

Phosphine oxides are widely used ligands in f-element chemistry. As a result of the oxophilic and Lewis acidic character of lanthanides and actinides, phosphine oxides coordinate readily, and are able to stabilise a variety of complexes in low and high oxidation states. ${ }^{30-35}$ Moreover, applications in catalysis and liquid-liquid extraction processes have been found. ${ }^{36}$ Therefore, the reaction of a benzene solution of the uranium boroxide complex $\mathbf{1}^{\mathbf{m}}$ with two equivalents of $\mathrm{OPPh}_{3}$ was carried out, Scheme 3. This leads to the formation of $\left[\mathrm{U}\left(\mathrm{OBMes}_{2}\right)_{3}\left(\mathrm{OPPh}_{3}\right)_{2}\right]\left(5^{\mathbf{m}}\right)$, which co-crystallised together with a minor by-product $\left[\mathrm{U}\left(\kappa^{2}-\{\mathrm{OB}(\mathrm{Mes})\}_{2} \mathrm{O}\right)\left(\mathrm{OBMes}_{2}\right)_{3}\right]\left(\mathbf{6}^{\mathbf{m}}\right) .^{7}$

The ${ }^{1} \mathrm{H}$ NMR spectrum of $5^{\mathbf{m}}$ in $\mathrm{C}_{6} \mathrm{D}_{6}$ contains six resonances which range from 6.9 to $1.87 \mathrm{ppm}$. The ${ }^{31} \mathrm{P}$ NMR spec-

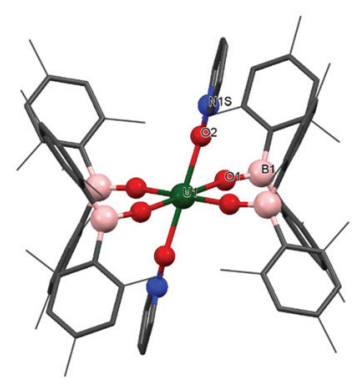

Fig. 3 Solid-state structure of $4^{\mathrm{m}}$. Hydrogens atoms are omitted and mesityl and pyridine oxide ligands are depicted as wireframe and capped sticks for clarity. trum shows a single broad resonance at $-17.83 \mathrm{ppm}$, and this is significantly shifted from the free $\mathrm{OPPh}_{3}$ resonance $(\sim 25 \mathrm{ppm})$ as a result of its proximity to the metal centre. Mass spectrometric analysis (APPI-MS) showed a molecular ion peak at $m / z=1589.77$ that corresponds to fragment $\left[5^{\mathbf{m}}\right]^{\cdot+}$. By-product $\left[\mathrm{U}\left(\kappa^{2}-\{\mathrm{OB}(\mathrm{Mes})\}_{2} \mathrm{O}\right)\left(\mathrm{OBMes}_{2}\right)_{3}\right]\left(6^{\mathbf{m}}\right)$ contains a coordinated boroxinato ligand, a cyclic anhydride of borinic acid, ${ }^{37}$ which is formally a product of ligand condensation, but probably formed from a contaminant in the ligand. Boroxines are rigid bidentate ligands which have drawn attention recently, mostly by forming complexes of main group elements, e.g. for $\mathrm{Al}^{38-40} \mathrm{Sn}$, Sb and $\mathrm{Bi}^{41-47}$ but also for transition metals such as $\mathrm{Mn},{ }^{48} \mathrm{Au}^{37,49}$ and $\mathrm{Pt}^{50}$

Single crystals of $5^{\mathbf{m}}$ and $6^{\mathbf{m}}$ were obtained by slow diffusion of hexanes into a benzene solution. Complex $\mathbf{5}^{\mathbf{m}}$ has an approximately trigonal bipyramidal coordination geometry (Fig. 4). The U-OPPh 3 bond lengths are 2.273(4) $\AA$ and 2.270(4) $\AA$, which are $\sim 0.1 \AA$ shorter than other $\mathrm{U}^{\mathrm{III}}-\mathrm{OPPh}_{3}$ distances previously reported. ${ }^{36,51}$ The U-O-P angles for the phosphine oxide ligands are $170.4(3)^{\circ}$ and $174.4(2)^{\circ}$ respectively, and the $\mathrm{O}_{4}-\mathrm{U}-\mathrm{O}_{5}$ angle is $176.62(13)^{\circ}$. These angles are similar to the angles in the known complex, $\left[\mathrm{U}\left(\mathrm{NPhAr}^{\mathrm{F}}\right)_{3}\left(\mathrm{OPPh}_{3}\right)_{2}\right] .{ }^{24}$ The $\mathrm{U}-\mathrm{O}_{\text {avg }}$ distance for the boroxide ligands is $2.124 \AA$, which is $\sim 0.07 \AA$ shorter than the $\mathrm{U}-\mathrm{O}$ bond lengths for the terminal boroxides in $\mathbf{1}^{\mathbf{m}}$ (mean $2.196 \AA$ ). Similarly, the average B-O distance is $1.345 \AA$ which is slightly shorter than complex $\mathbf{1}^{\mathbf{m}}$ (mean $1.351 \AA$ ). Moreover, the mean $\mathrm{U}-\mathrm{O}-\mathrm{B}$ angle is $176.0^{\circ}$, and this is less bent than the terminal boroxide in $\mathbf{1}^{\mathbf{m}}$ (mean $171.6^{\circ}$ ). Complex $6^{\mathbf{m}}$ has a nearly square pyramidal coordination geometry. The metallacycle formed from the $[\mathrm{OBOBO}]^{2-}$ unit has similarities with early metal complexes such as $\left(\eta^{2} \text {-catechol- } \mu \text {-catecholborate }\right)_{3} \operatorname{ThCl}\left(\mathrm{C}_{4} \mathrm{H}_{8} \mathrm{O}\right)_{3} \cdot \mathrm{C}_{4} \mathrm{H}_{8} \mathrm{O}$ that are coordinated by alternating catechol and catecholborate groups in a hexaoxo trianionic macrocyclic structure, observed for $\mathrm{Zr}$, Nd, Sm, U and Th centres. ${ }^{52,53}$ For the boroxine ligand, the U-O bond distances are 2.193(4) $\AA$ and 2.191(4) $\AA$. The B-O distances range from 1.342(9)-1.370(9) A, which are in the same range as previously reported for main group boroxines. The six-membered ring unit has internal angles close to $120^{\circ}$, except for the $\mathrm{O}_{9}-\mathrm{U}-\mathrm{O}_{11}$ bond which is much smaller, being only $77.40(16)^{\circ}$. The boroxide ligands have similar $\mathrm{U}-\mathrm{O}$ and $\mathrm{B}-\mathrm{O}$ bond lengths $\left(\mathrm{U}-\mathrm{O}_{\text {avg }} 2.172 \AA\right.$, $\mathrm{B}-\mathrm{O}_{\text {avg }}$ $1.316 \AA$ ) to the terminal boroxides in $\mathbf{1}^{\mathrm{m}}$ (mean U-O 2.196 ̊,

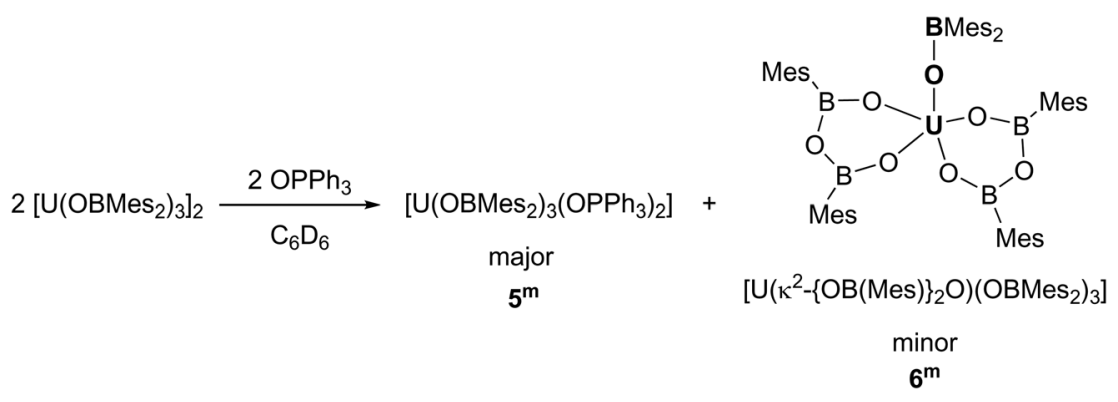

Scheme 3 Synthesis of compounds $5^{m}$ and $6^{m}$. 


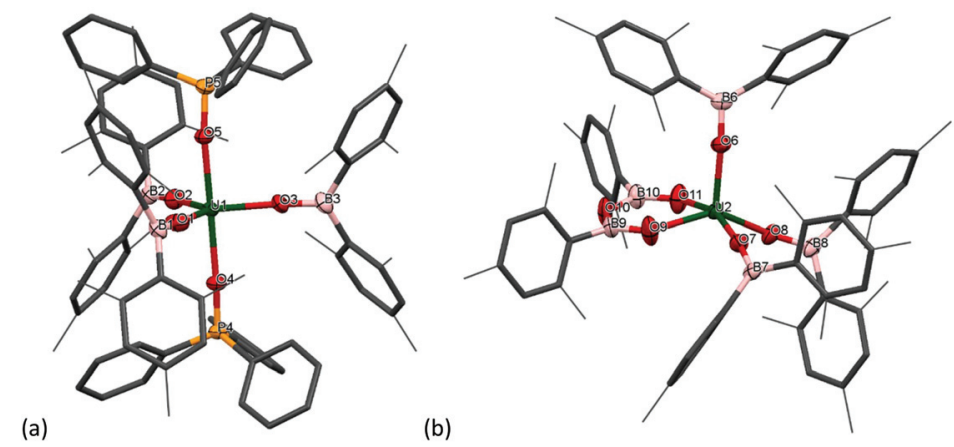

Fig. 4 Solid-state structure of (a) $5^{\mathrm{m}}$ and (b) $6^{\mathrm{m}}$. Mesityl and phenyl ligands are depicted as capped sticks and wireframe for clarity. Hydrogen atoms are omitted. The thermal ellipsoids are displayed at $50 \%$ probability.

B-O $1.351 \AA$ A). Finally, the U-O-B angles for the boroxides range from $155.2(4)^{\circ}$ to $168.7(4)^{\circ}$, which are significantly more bent than for the terminal boroxides in $\mathbf{1}^{\mathbf{m}}$ (mean $171.6^{\circ}$ ).

\section{Elemental sulfur}

The reactivity of chalcogens and chalcogenides with actinide complexes has gained attention recently. Of particular interest is the potential of the metal-ligand bonding in these more polarisable systems to advance our understanding of the degree of covalency in uranium-ligand bonds, as this can provide insights into better separation of actinides from lanthanides in spent nuclear fuel. ${ }^{54-58}$ Addition of 0.5 equivalents of $\mathrm{S}_{8}$ to a stirring solution of $\left[\mathrm{U}\left(\mathrm{OBMes}_{2}\right)_{3}\right]_{2} \mathbf{1}^{\mathbf{m}}$ leads to the formation of $\left[\left\{\left(\mathrm{OBMes}_{2}\right)_{3} U\right\}_{2}\left(\mu-\eta^{2}: \eta^{2}-\mathrm{S}_{2}\right)_{2}\right]\left(7^{\mathbf{m}}\right)$, which contains two independent bridging $\mathrm{S}_{2}$ units. There is only one other example in the literature of a uranium complex featuring two bridging $\mathrm{S}_{2}$ units, $\left[\left\{\left(\left[{ }^{\mathrm{Ad}} \mathrm{ArO}\right]_{3} \mathrm{~N}\right) \mathrm{U}\right\}_{2}\left(\mu-\eta^{2}: \eta^{2}-\mathrm{S}_{2}\right)_{2}\right] .{ }^{59}$ The ${ }^{1} \mathrm{H}$ NMR spectrum contains a set of resonances corresponding to the $\mathrm{OBMes}_{2}$ ligand, indicating one ligand environment. Mass spectrometric analysis shows the molecular ion at $\mathrm{m} / \mathrm{z}=$ 1033.56 that corresponds to the $[\mathrm{M}]^{\circ+}$ fragment, $\left[\left\{\left(\mathrm{OBMes}_{2}\right)_{3} \mathrm{U}\right\}\right.$ $\left.\left(\mu-\eta^{2}: \eta^{2}-S_{2}\right)\right]^{\bullet+}$. Translucent red crystals of the sulfur-bridged complex $7^{\mathbf{m}}$ suitable for XRD analysis were grown from a concentrated toluene solution.

Fig. 5 shows the molecular structure of $7^{\mathbf{m}}$, confirming the formation of a uranium dimer with two $S_{2}$ units. Each uranium ion has a distorted pentagonal bipyramidal coordination geometry. The $\mathrm{S}_{1 \mathrm{~B}}-\mathrm{S}_{2 \mathrm{~B}}$ bond length is 2.050(2) $\AA$, which is a typical value for a $\mathrm{S}-\mathrm{S}$ single bond, and comparable to $\mathrm{H}_{2} \mathrm{~S}_{2}$ with a S-S bond length of $2.055 \AA .{ }^{44}$ The S $\cdots \mathrm{S}$ distance between the two units is $3.491 \AA$, excluding the possibility of a $\mathrm{S}_{4}{ }^{2-}$ unit.

Thus, although one would normally anticipate a $\mathrm{U}^{\mathrm{IV}}$ formal oxidation state product to form from the reduction of sulfur, here the $\mathrm{U}^{\mathrm{V}}$ assignment appears more appropriate. The ligands are both identified as bridging persulfido $\left(\mathrm{S}_{2}{ }^{2-}\right)$, giving a formal $\mathrm{U}^{\mathrm{V}}$ oxidation state for $7^{\mathbf{m}}$ by comparison of the U-E bonds. Previously reported uranium persulfido $\mathrm{S}_{2}{ }^{2-}$ complexes show S-S distances from $2.050 \AA$ to $2.103 \AA{ }^{60-68}$ Previously reported transition metal supersulfido $\mathrm{S}_{2}{ }^{-}$complexes show $\mathrm{S}-\mathrm{S}$

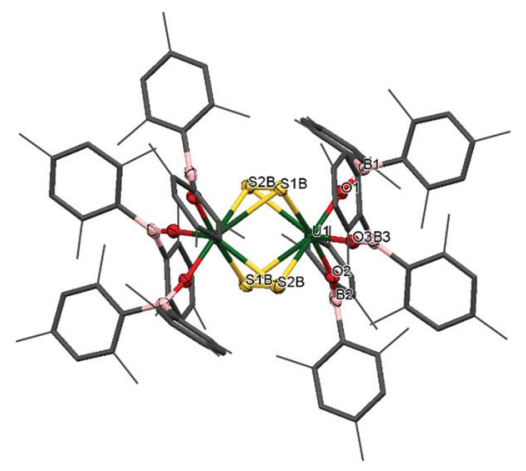

Fig. 5 Solid-state structure of complex $7^{m}$. Mesityl ligands are depicted as capped sticks and wireframe for clarity. Hydrogen atoms are omitted. The thermal ellipsoids are displayed at $50 \%$ probability.

distances from 1.944 to $2.023 \AA^{69-72}$ Furthermore, the $\mathrm{U}-\mathrm{O}_{\text {avg }}$ bond length is $2.078 \AA$, which is significantly shorter than the $\mathrm{U}-\mathrm{O}$ bond lengths for the terminal boroxides in $\mathrm{U}^{\mathrm{III}} \mathbf{1}^{\mathbf{m}}$ (mean $2.196 \AA$ ), and in $2^{\mathbf{m}}$ (mean $2.119 \AA$ ), also suggesting a formal oxidation state of +5 is most likely. Moreover, the $\mathrm{B}-\mathrm{O}$ average distance is $1.359 \AA$, which is slightly longer than for complexes $\mathbf{1}^{\mathbf{m}}$ and $2^{\mathbf{m}}$ (mean $1.351 \AA$ and $1.356 \AA$ respectively). The U-O-B angle of $165(3)^{\circ}$ is much more bent than for the terminal boroxide ligands in $\mathbf{1}^{\mathbf{m}}$ (mean $171.6^{\circ}$ ), which is reasonable if more electron density from the $\mathrm{O}$ atoms are being distributed into a backdonation from the uranium centres to the sulfido ligands.

\section{DCC, $N, N^{\prime}$-dicyclohexylcarbodiimide}

The direct reaction of carbodiimides such as $\left(\mathrm{DCC}=\mathrm{N}, \mathrm{N}^{\prime}-\right.$ dicyclohexylcarbodiimide) with uranium was first reported in $2009 .^{73}$ The aim of these reactions was to insert a carbodiimide into a U-C ligand bond in order to increase the steric crowding in organouranium complexes. Since then, several examples of insertion of carbodiimides into metal-ligand $\sigma$-bonds have been reported, ${ }^{74-77}$ as well as further reactivity towards small molecules with these ligands. ${ }^{78-80}$ Moreover, reactions of carbodiimides have also led to the formation of metallacycles that 
have unique structural properties and possible applications in catalysis. ${ }^{81-84}$

$$
\begin{aligned}
& 1 / 2\left[\mathrm{U}\left(\mathrm{OBMes}_{2}\right)_{3}\right]_{2}+2 \mathrm{DCC} \\
& 1^{\mathrm{m}}
\end{aligned}
$$

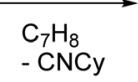

$8^{m}$

Dropwise addition of a toluene solution of DCC to a dark purple toluene solution of $\mathbf{1}^{\mathbf{m}}$ produced a green solution from which $\left[\mathrm{U}\left\{\eta^{2}-\mathrm{N}(\mathrm{Cy}) \mathrm{C}(=\mathrm{NCy}) \mathrm{N}(\mathrm{Cy})\right\}\left(\mathrm{OBMes}_{2}\right)_{3}\right] \quad\left(\mathbf{8}^{\mathbf{m}}, \mathrm{Cy}=\right.$ cyclo$\mathrm{C}_{6} \mathrm{H}_{11}$ ), eqn (2), was isolated in close to quantitative yield after work-up. Mass spectroscopic analysis confirms the formulation of $\mathbf{8}^{\mathbf{m}}$ as the molecular ion at $m / z=1337.85$ that corresponds to $[\mathrm{M}+\mathrm{H}]^{+}$was observed. Single crystals for XRD characterisation could not be obtained. The ${ }^{1} \mathrm{H}$ NMR spectrum of $\mathbf{8}^{\mathbf{m}}$ has resonances from 58.36 to $-10.62 \mathrm{ppm}$, widely shifted out of the diamagnetic region by proximity to the paramagnetic uranium centre. Taken together, the characterising data show that the carbodiimide has been coupled by the reducing $\mathrm{U}$ centre to form the rearranged cyclohexyl-substituted guanidinate ligand via loss of cyclo-hexylisonitrile. This presumably occurs similarly to the procedure reported for the reaction that converts $\left[\mathrm{U}\left(\eta^{5}-\mathrm{C}_{5} \mathrm{Me}_{5}\right)_{2}\left(\eta^{2}\right.\right.$-bipy $\left.)\right]$ to $\left[\mathrm{U}\left(\eta^{5}-\mathrm{C}_{5} \mathrm{Me}_{5}\right)_{2}\left\{\eta^{2}-\mathrm{N}(\mathrm{Cy}) \mathrm{C}(=\mathrm{NCy}) \mathrm{N}(\mathrm{Cy})\right\}\right] \quad$ via extrusion of [CyNC] from a coordinated DCC ligand then a [2+2] addition to the transiently formed $\mathrm{U}^{\mathrm{V}}=\mathrm{NCy}$ group. ${ }^{81}$ The fact that this forms from the $\mathrm{U}^{\mathrm{IV}}$ product again supports the stabilising effect of this ligand on the higher formal oxidation states of uranium.

\section{Reactions of $1^{\mathrm{t}}$ with $\mathrm{CO}$ and $\mathrm{CO}_{2}$}

In contrast to $\mathbf{1}^{\mathbf{m}}$, the bulkier $\mathbf{1}^{\mathrm{t}}$ reduces both $\mathrm{CO}$ and $\mathrm{CO}_{2}$; reaction with the former affording the known oxidation product $2^{\mathrm{t}}$, and the latter affording a bridging carbonate $\mathbf{9}^{\mathbf{t}}$, although the yields are moderate and minimal respectively, Scheme 4.

Exposure of a degassed purple-brown solution of $\mathbf{1}^{\mathbf{t}}$ in cyclopentane to a $1 \mathrm{~atm}$ pressure of $\mathrm{CO}_{2}$ results in the immediate formation of a green solution. Colourless crystals can be obtained upon allowing the solution to stand at room temperature overnight. The single crystals collected were of sufficient quality to obtain connectivity information by single crystal $\mathrm{XRD}$ analysis to identify the product as $\left[\left(\mu-\mathrm{CO}_{3}\right)\left\{\mathrm{U}(\mathrm{OBTrip})_{3}\right\}_{2}\right]$ $\left(9^{t}\right)$. The solid-state structure is reminiscent of other bimetallic carbonate-bridged uranium(rv) complexes, ${ }^{85,86}$ with a disordered bridging carbonate linking the uranium centres with distorted trigonal bipyramidal geometries. The boroxide

$$
\begin{aligned}
& \left.\left.\left[\mathrm{U}(\mathrm{OBTrip})_{2}\right)_{3}\right]_{2} \underset{\mathrm{C}_{6} \mathrm{H}_{6}}{\stackrel{+\mathrm{CO}}{\longrightarrow}} \mathrm{U}(\mathrm{OBTrip})_{2}\right)_{4} \\
& \underset{\mathrm{C}_{5} \mathrm{H}_{10}}{\stackrel{\mathrm{CO}_{2}}{\longrightarrow}}\left[\left(\mu-\mathrm{CO}_{3}\right)\left\{\mathrm{U}(\mathrm{OBTrip})_{2}\right)_{3}\right]
\end{aligned}
$$

Scheme 4 Reactions of complex $1^{\mathrm{t}}$ with $\mathrm{CO}$ and $\mathrm{CO}_{2}$. ligands are staggered along the $\mathrm{U}_{1}-\mathrm{C}_{1}-\mathrm{U}_{1 \mathrm{~A}}$ axis to minimise the steric interactions of the ligands. The formation of carbonate bridged bimetallic uranium(Iv) complexes has been postulated to proceed via a terminal uranium(v) oxo. ${ }^{87,88}$

Comparatively, exposure of $\mathbf{1}^{\mathrm{t}}$ solutions to a $\mathrm{CO}$ atmosphere only results in decomposition to the homoleptic U(Iv) boroxide complex $2^{\mathrm{t}}$ and no CO containing products could be identified.

\section{Formation of complexes $\left[\mathrm{U}\left(\mathrm{OBMes}_{2}\right) \mathrm{N}_{3}{ }_{3}\right] \mathbf{1 1}^{\mathrm{m}}$ and $\left[\mathrm{U}\left(\mathrm{OBTrip}_{2}\right)\right.$} $\left.\mathrm{N}_{3}{ }_{3}\right] 11^{\mathrm{t}}$

As mentioned previously, any traces of the metallacycle $\left[\mathrm{UN}_{2}{ }_{2}\left\{\mathrm{\kappa}^{2}-\mathrm{N}^{\prime}\left(\mathrm{SiMe}_{2} \mathrm{CH}_{2}\right)\right\}\right]$ in the synthesis of complexes $\mathbf{1}^{\mathbf{m}}$ and $\mathbf{1}^{\mathbf{t}}$ leads to the formation of complexes $\left[\mathrm{UN}_{3}{ }_{3}\left(\mathrm{OBMes}_{2}\right)\right]\left(\mathbf{1 1}^{\mathbf{m}}\right)$ and $\left[\mathrm{UN}_{3}{ }_{3}\left(\mathrm{OBTrip}_{2}\right)\right]\left(\mathbf{1 1}^{\mathrm{t}}\right)$. Moreover, an alternative synthesis for complex $\mathbf{1 1}^{\mathbf{m}}$ is achieved by addition of just one equivalent of $\mathrm{HOBMes}_{2}$ to an orange-brown solution of the uranium metallacycle $\left[\mathrm{UN}_{2}{ }_{2}\left\{\mathrm{~K}^{2}-\mathrm{N}^{\prime}\left(\mathrm{SiMe}_{2} \mathrm{CH}_{2}\right)\right\}\right]$, which provides a brown solution from which $\left[\mathrm{UN}_{3}{ }_{3}\left(\mathrm{OBMes}_{2}\right)\right]\left(\mathbf{1 1}^{\mathbf{m}}\right)$ can be isolated as brown solids (Scheme 5). Formation of complex $\mathbf{1 1}^{\mathbf{m}}$ was confirmed by ${ }^{1} \mathrm{H}$ and ${ }^{29} \mathrm{Si}$ spectroscopies, elemental analysis and single crystal XRD analysis.

The ${ }^{1} \mathrm{H}$ NMR spectrum shows a paramagnetically shifted resonance at $-6.56 \mathrm{ppm}$, which corresponds to the methyl groups in the tris(silylamide) ligand, and three smaller sets of resonances for the boroxide ligand. Moreover, the ${ }^{29} \mathrm{Si}$ NMR resonances shift from -74.46 and $-81.84 \mathrm{ppm}$ for the uranium metallacycle to $-131.74 \mathrm{ppm}$ for complex $\mathbf{1 1}^{\mathbf{m}}$.

Single crystal XRD analysis revealed that the solid-state structure of complexes $\mathbf{1 1}^{\mathbf{m}}$ and $\mathbf{1 1}^{\mathbf{t}}$ have a distorted tetrahedral coordination environment where the uranium centre is coordinated by one terminal boroxide ligand and three silylamide groups (Fig. 6). Crystals of complex $\mathbf{1 1}^{\mathbf{m}}$ suitable for

$$
\left[\mathrm{UN}_{2}\left\{\mathrm{~K}^{2}-\mathrm{N}^{\prime}\left(\mathrm{SiMe}_{2} \mathrm{CH}_{2}\right)\right\}\right] \frac{\mathrm{HOBMes}_{2}}{\mathrm{C}_{6} \mathrm{H}_{6}}\left[\begin{array}{c}
\mathbf{1} \\
11^{\mathrm{m}}
\end{array}\right.
$$

Scheme 5 Synthesis of heteroleptic complex $11^{\mathrm{m}}$.
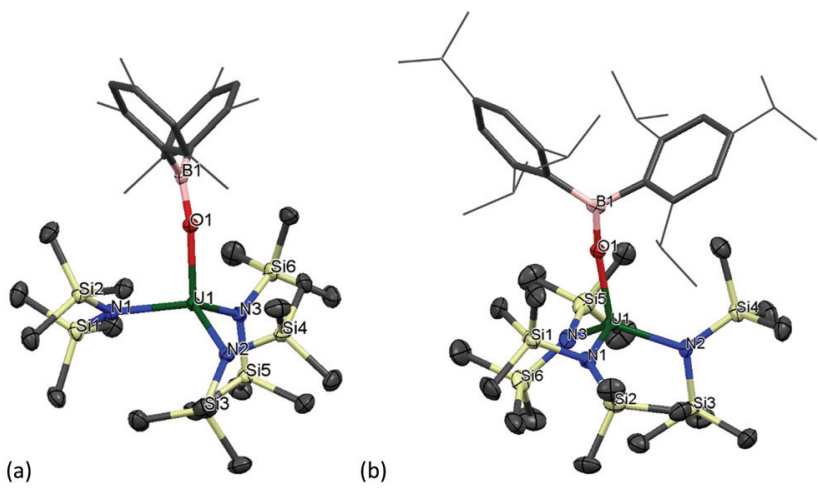

Fig. 6 Solid-state structure of (a) $11^{\mathrm{m}}$ and (b) $11^{\mathrm{t}}$. Mesityl and triisopropylphenyl ligands are depicted as capped sticks and wireframe for clarity. Hydrogen atoms are omitted. The thermal ellipsoids are displayed at $50 \%$ probability. 
XRD analysis are obtained from a concentrated toluene solution. The average $\mathrm{U}-\mathrm{N}_{\mathrm{avg}}$ bond length is $2.268 \AA$, which is $\sim 0.03 \AA$ shorter than that of the previously reported complex $\left[\mathrm{U}\left(\mathrm{N}\left(\mathrm{SiMe}_{3}\right)_{4}\right],{ }^{89}\right.$ which is reasonable if more electron density is being distributed to the boroxide ligand and more electron density is being pulled from the tris(silylamide) ligands, thus decreasing the $\mathrm{U}-\mathrm{N}$ bond length. The $\mathrm{B}-\mathrm{O}_{\text {avg }}$ is 1.365(4) $\mathrm{A}$, which is longer than the $\mathrm{B}-\mathrm{O}_{\text {avg }}$ bond length in complex $\mathbf{1}^{\mathbf{m}}$ (mean 1.351 $\mathrm{A}$ ). Moreover, the $\mathrm{N}-\mathrm{U}-\mathrm{N}$ angles are $105.00(8)^{\circ}$, $113.72(8)^{\circ}$ and $116.96(9)^{\circ}$, which are in the same range as for $\left[\mathrm{U}\left(\mathrm{N}\left(\mathrm{SiMe}_{3}\right)_{4}\right]\right.$. The U-O distance is $2.1559(18) \AA$, which is slightly shorter than the $\mathrm{U}-\mathrm{O}$ distance in the terminal boroxides for complex $\mathbf{1}^{\mathbf{m}}\left(\mathrm{U}-\mathrm{O}_{\text {avg }}\right.$ is $2.196 \AA$ ) but longer than the $\mathrm{U}-\mathrm{O}_{\text {avg }}$ for $2^{\mathrm{m}}(2.144 \AA)$. The U-O-B angle is $167.23(19)^{\circ}$, which is in the same range as $\mathrm{U}-\mathrm{O}-\mathrm{B}$ angles for the terminal boroxides in complex 1 (mean 171.6 $)$. Colourless crystals of complex $11^{\mathrm{t}}$ suitable for $\mathrm{X}$-ray diffraction analysis were obtained from a concentrated benzene solution upon standing at room temperature. The U-O distance amounts to 2.167(3) A, which is longer than that of $\mathrm{OB}(\mathrm{Mes})_{2}$-coordinating analogue $\mathbf{1 1}^{\mathbf{m}}$. The mean U-N bond length is 2.272(3) $\AA$, which is longer than complex $11^{\mathbf{m}}$ and the previously reported $\left[\mathrm{U}\left(\mathrm{N}\left(\mathrm{SiMe}_{3}\right)_{4}\right]^{89}\right.$ Bond length of B-O (1.365(5) $\AA$ ) is essentially the same as that of U(IV) complex $2^{\mathrm{t}}$ (1.364(7) $\AA$ ). Bond angle of U-O-B is $169.8(3)^{\circ}$, which is in the same range as the $\mathrm{U}-\mathrm{O}-\mathrm{B}$ angle in complex $\mathbf{1 1}^{\mathbf{m}}$.

\section{Conclusions}

Diaryl boroxide ligands are capable ligands for both $\mathrm{U}^{\mathrm{III}}$ and $\mathrm{U}^{\mathrm{IV}}$ cations but the $\mathrm{U}^{\mathrm{III}}$ complexes are particularly air-sensitive and decompose readily to different $\mathrm{U}^{\mathrm{IV}}$ complexes depending on the conditions. We suggest that rather than working in tandem as a second Lewis acidic reaction centre, the role of the boron is simply to remove electron density from the reducing $\mathrm{U}^{\mathrm{III}}$ centre in $\mathbf{1}$ to such an extent that it does not efficiently reduce an incoming substrate, and neither the $\mathrm{U}$ or $\mathrm{B}$ centres in these complexes can bind a phosphine. No reactions were observed for $\mathbf{1}^{\mathbf{m}}$ with carbon monoxide or carbon dioxide at ambient pressure and temperature, underlining these observations. Reactions at elevated temperatures simply result in the decomposition of $\mathbf{1}^{\mathbf{m}}$. Meanwhile, with larger boroxide aryl substituents, complex $\mathbf{1}^{\mathbf{t}}$ exhibits greater thermal stability compared to less encumbered $\mathbf{1}^{\mathbf{m}}$ and greater reactivity with the less reducible, smaller carbon oxides, but lower reactivity with the less reactive, but slightly larger small molecules tested so far. In general, the reactions of $\mathbf{1}^{\mathbf{m}}$ with small molecules and other substrates give low yields due to the extensive formation of $3^{\mathbf{m}}$ from traces of oxygen, or perhaps also reactions with vacuum grease and/or glassware. Qualitatively, the sum of these reactions suggest that the $\mathrm{OBAr}_{2}$ ligands make the $\mathrm{UX}_{3}$ centre less strongly reducing than the analogous aryloxide ligands ODtbp, which is in line with expectation, but we caution that due to the additional modes of reactivity available to the boron centre, a direct and more precise estimate of the relative oxidation potentials that the ligands impose on the $\mathrm{U}(\mathrm{III})$ centre in each complex is more difficult to make. For example, the aryloxide complexes $\mathrm{U}(\mathrm{OAr})_{3}$ reductively activate $\mathrm{N}_{2}$ but this has not been observed in the boroxide system, although the increased capacity for both $\mathrm{OBAr}_{2}$ ligands to bridge to a second $\mathrm{U}$ centre hampers the comparison. Work on finding a more quantitive measure for this is in progress. The isolation of small quantity of a $\mu$-carbonate product $\left.\left[\left(\mu-\mathrm{CO}_{3}\right)\left\{\mathrm{U}(\mathrm{OBTrip})_{2}\right)_{3}\right\}_{2}\right]$ suggests there are opportunities however, and work is in progress to identify new substrates that could be usefully activated by the combination of the two potentially Lewis acidic centres in this system.

\section{Experimental section}

\section{$\left[\mathrm{U}\left(\mathrm{OBMes}_{2}\right)_{3}\right]_{2}\left(\mathbf{1}^{\mathrm{m}}\right)$}

A Schlenk flask was charged with $\mathrm{U}\left[\mathrm{N}\left(\mathrm{SiMe}_{3}\right)_{2}\right]_{3}(1.08 \mathrm{~g}$, $1.5 \mathrm{mmol}$ ) and $\mathrm{HOBMes}_{2}$ (1.20 g, $4.5 \mathrm{mmol}, 3 \mathrm{eq}$.) and a stir bar. The reaction mixture was dissolved in toluene $(40 \mathrm{~mL})$ to yield a purple solution, which was allowed to stir at room temperature for 4 hours. Volatiles were removed by evaporation to dryness. The residue was washed with cold hexane $\left(-78^{\circ} \mathrm{C}\right.$, $4 \mathrm{~mL}$ ) and recrystallized from hexane providing dark purple block crystals suitable for single-crystal X-ray crystallography. Yield: $634 \mathrm{mg}, 41 \%$.

${ }^{1} \mathrm{H} \quad \mathrm{NMR} \quad\left(500 \mathrm{MHz}, \mathrm{C}_{6} \mathrm{D}_{6}\right): \delta_{\mathrm{H}} 8.29$ (Ar-H terminal Mes, $16 \mathrm{H}) ; 7.20\left(o-\mathrm{CH}_{3}\right.$ terminal Mes, $\left.48 \mathrm{H}\right) ; 2.53\left(p-\mathrm{CH}_{3}\right.$ terminal Mes, 24H); $-3.71\left(o-\mathrm{CH}_{3}\right.$ bridging Mes, $\left.12 \mathrm{H}\right) ;-9.20$ (Ar-H and p- $\mathrm{CH}_{3}$ bridging Mes, 20H); -15.13 (o- $\mathrm{CH}_{3}$ bridging Mes, $12 \mathrm{H}$ ).

${ }^{11} \mathrm{~B}$ NMR (160.46 MHz, $\mathrm{C}_{6} \mathrm{D}_{6}$ ): $\delta_{\mathrm{B}} 73.65$ (OBMes). The latter is a tentative assignment. The sample analysed was dissolved single crystals, but this resonance is close to that of hydrolysed ligand so it may be the other resonance is not observed in the window.

MS (APPI): $m / z=1033\left([\mathrm{M}]^{\bullet+}\left[\mathrm{U}\left(\mathrm{OBMes}_{2}\right)_{3}\right]\right) \mathrm{C}_{54} \mathrm{H}_{66} \mathrm{~B}_{3} \mathrm{O}_{3} \mathrm{U}^{*+}$ $[\mathrm{M}]^{\bullet+}$ requires 1033.5799 , found $1033.5675(+12.4 \mathrm{ppm})$.

FTIR $\left(\mathrm{cm}^{-1}\right): 3612,2728,1721,1608,1552,1280,1228$, 1176, 1151, 1081, 1029, 960, 928, 847, 745, 672.

Anal. calc for $\mathrm{C}_{104} \mathrm{H}_{132} \mathrm{~B}_{6} \mathrm{O}_{6} \mathrm{U}_{2}$ : C, $62.75 \mathrm{H}, 6.44 \mathrm{~N}, 0.00 \%$. Found: C, $62.63 \mathrm{H}, 6.47 \mathrm{~N}, 0.00 \%$.

\section{$\left[\mathrm{U}\left(\mathrm{OBMes}_{2}\right)_{4}\right]\left(2^{\mathrm{m}}\right)$}

A toluene solution $(1.5 \mathrm{~mL})$ of $\mathrm{NaOBMes}_{2}(115 \mathrm{mg}, 0.4 \mathrm{mmol}$, 4 eq.) was added dropwise over $10 \mathrm{~min}$ to a solution of $\mathrm{UI}_{4}$ (dioxane $)_{2}(92 \mathrm{mg}, 0.1 \mathrm{mmol})$ in toluene $(1.5 \mathrm{~mL})$ in a $7 \mathrm{~cm}^{3}$ vial with stirring for 18 hours. The reaction was centrifuged and filtered. Colourless plates suitable for single-crystal X-ray crystallography were grown from slow diffusion of hexanes into the reaction mixture. Yield: $16.7 \mathrm{mg}$, $12 \%$.

${ }^{1} \mathrm{H}$ NMR (500 MHz, $\mathrm{C}_{6} \mathrm{D}_{6}$ ): $\delta_{\mathrm{H}} 6.71$ (Ar-H Mes, 16H); 2.15 $\left(o-\mathrm{CH}_{3}\right.$ Mes, $\left.48 \mathrm{H}\right) ; 1.99 \quad\left(p-\mathrm{CH}_{3} \quad \mathrm{Mes}, \quad 24 \mathrm{H}\right) .{ }^{11} \mathrm{~B} \quad \mathrm{NMR}$ (160.46 MHz, $\mathrm{C}_{6} \mathrm{D}_{6}$ ): not observed in the window +130--130 ppm. 
MS (APPI): $m / z=1299\left([\mathrm{M}]^{++}\left[\mathrm{U}\left(\mathrm{OBMes}_{2}\right)_{4}\right]\right) \cdot \mathrm{C}_{72} \mathrm{H}_{88} \mathrm{~B}_{4} \mathrm{O}_{4} \mathrm{U}$ $[\mathrm{M}]^{++}$requires 1298.7563, found $1298.7595(-3.2 \mathrm{ppm})$.

\section{$\left[\mathrm{U}\left(\text { OBTrip }_{2}\right)_{3}\right]_{2}\left(1^{\mathrm{t}}\right)\left[\mathrm{U}\left(\text { OBTrip }_{2}\right)_{4}\right]\left(2^{\mathrm{t}}\right)$}

HOBTrip $_{2}(104 \mathrm{mg}, 0.24 \mathrm{mmol})$ and $\mathrm{UN}_{3}(72 \mathrm{mg}, 0.1 \mathrm{mmol})$ were dissolved in benzene $(0.8 \mathrm{~mL})$ in a $7 \mathrm{~mL}$ vial. The resulting dark red solution was stored at room temperature for $60 \mathrm{~h}$ during which time $\mathrm{U}\left(\mathrm{OBTrip}_{2}\right)_{4} 2^{\mathrm{t}}$ crystallised as dark red crystals which can be isolated and washed with benzene $(0.3 \mathrm{~mL} \times$ $3)$. A second crop of $2^{\mathbf{t}}$ was isolated from the mother liquor to give a combined yield of $25 \%$ of $2^{\mathrm{t}}(30 \mathrm{mg}, 0.02 \mathrm{mmol})$. Complex $\mathbf{1}^{\mathrm{t}}$ (39 mg, $0.013 \mathrm{mmol}, 32 \%$ yield) was isolated after removal of volatiles from the mother liquor.

Characterization of complex $1^{\mathrm{t}}$ :

${ }^{1} \mathrm{H}$ NMR $\left(500 \mathrm{MHz}, \mathrm{C}_{6} \mathrm{D}_{6}\right): \delta 8.10$ (br-s, $\left.12 \mathrm{H}, \mathrm{Ar}-\mathrm{H}\right), 2.90$ (brs, $18 \mathrm{H}, \mathrm{CH}), 1.45$ (br-s, 108H, Me). ${ }^{11} \mathrm{~B}$ NMR $(160.46 \mathrm{MHz}$, $\mathrm{C}_{6} \mathrm{D}_{6}$ ): 110.19 (O-B-Ar). Repeated submissions of samples for elemental analysis did not yield reasonable data.

Characterization of complex $\mathbf{2}^{\text {t }}$ :

${ }^{1} \mathrm{H}$ NMR (500 MHz, $\left.\mathrm{C}_{6} \mathrm{D}_{6}\right): \delta 44.14(\mathrm{~s}, 3 \mathrm{H}, \mathrm{Ar}-\mathrm{H}), 17.87$ (s, $3 \mathrm{H}, \mathrm{Ar}-\mathrm{H}), 10.66(\mathrm{~s}, 4 \mathrm{H}, \mathrm{Ar}-\mathrm{H}), 8.86(\mathrm{~s}, 6 \mathrm{Ar}-\mathrm{H}+4 \mathrm{CH}), 7.41(\mathrm{~s}$, $8 \mathrm{H}, \mathrm{CH}), 6.74(\mathrm{~s}, 4 \mathrm{H}, \mathrm{CH}), 5.46(\mathrm{~s}, 4 \mathrm{H}, \mathrm{CH}), 4.78(\mathrm{~s}, 4 \mathrm{H}, \mathrm{CH})$, $4.13\left(\mathrm{~s}, 12 \mathrm{H}, \mathrm{CH}_{3}\right), 1.49\left(\mathrm{~m}, 24 \mathrm{H}, \mathrm{CH}_{3}\right), 1.24\left(\mathrm{~s}, 24 \mathrm{H}, \mathrm{CH}_{3}\right), 0.52$ $\left(\mathrm{d}, J=6 \mathrm{~Hz}, 12 \mathrm{H}, \mathrm{CH}_{3}\right), 0.25\left(\mathrm{~d}, J=6 \mathrm{~Hz}, 12 \mathrm{H}, \mathrm{CH}_{3}\right), 0.02(\mathrm{~d}, J=$ $\left.6 \mathrm{~Hz}, 9 \mathrm{H}, \mathrm{CH}_{3}\right),-1.34\left(\mathrm{~s}, 3 \mathrm{H}, \mathrm{CH}_{3}\right),-3.43\left(\mathrm{~s}, 12 \mathrm{H}, \mathrm{CH}_{3}\right),-4.29$ (s, $\left.12 \mathrm{H}, \mathrm{CH}_{3}\right),-13.75\left(\mathrm{~s}, 12 \mathrm{H}, \mathrm{CH}_{3}\right),-16.19\left(\mathrm{~s}, 9 \mathrm{H}, \mathrm{CH}_{3}\right)$, $-18.40\left(\mathrm{~s}, 3 \mathrm{H}, \mathrm{CH}_{3}\right) .{ }^{11} \mathrm{~B}$ NMR $\left(160.46 \mathrm{MHz}, \mathrm{C}_{6} \mathrm{D}_{6}\right)$ : no obvious resonance in the range of $230-40 \mathrm{ppm}$. Repeated submissions of samples for elemental analysis did not yield reasonable data.

\section{$\left[\mathrm{U}\left(\mathrm{OBTrip}_{2}\right)_{3}\left(\mathrm{OEt}_{2}\right)\right]\left(\mathbf{1}^{\mathrm{t}}-\mathrm{OEt}_{2}\right)$}

A solution of $\mathrm{HOBTrip}_{2}(326 \mathrm{mg}, 0.75 \mathrm{mmol})$ in $\mathrm{Et}_{2} \mathrm{O}(1 \mathrm{~mL})$ was added dropwise to solution of $\mathrm{UN}^{\prime \prime}{ }_{3}(216 \mathrm{mg}, 0.3 \mathrm{mmol})$ in $\mathrm{Et}_{2} \mathrm{O}(1 \mathrm{~mL})$ in a $7 \mathrm{~mL}$ vial. The resulting dark red solution was stirred at room temperature for $0.5 \mathrm{~h}$, which was left at $-30^{\circ} \mathrm{C}$ for a further $c a .60 \mathrm{~h}$. A brown precipitate was separated and washed with $\mathrm{Et}_{2} \mathrm{O}(0.5 \mathrm{~mL} \times 3)$ as complex $\mathbf{1 1}^{\mathrm{t}}$ (see below). The dark red mother liquid was concentrated, and left for standing, which gave complex 1 $\mathbf{1}^{\mathrm{t}} \mathbf{O E t}_{\mathbf{2}}(46 \mathrm{mg}, 0.029 \mathrm{mmol}$ ) as darkred crystals. The isolated yield is low due to the very high solubility of the product.

${ }^{1} \mathrm{H}$ NMR $\left(500 \mathrm{MHz}, \mathrm{C}_{6} \mathrm{D}_{6}\right): \delta 8.94(\mathrm{br}, 12 \mathrm{H}, \mathrm{Ar}-\mathrm{H}), 3.56$ (br-s, 18H, CH), 1.73 (br-s, 108H, Me). ${ }^{11} \mathrm{~B}$ NMR (160.46 MHz, $\mathrm{C}_{6} \mathrm{D}_{6}$ ): not observed in the window $+130-130 \mathrm{ppm}$. No reasonable elemental analysis data were obtained despite repeated trials.

$\left[\mathrm{OU}\left(\mathrm{OBMes}_{2}\right)_{3}\right]_{n}\left(3^{\mathrm{m}}\right)$

Method A. This product is observed when the complex $\left[\mathrm{U}\left(\mathrm{OBMes}_{2}\right)_{2}\left(\mu-\mathrm{OBMes}_{2}\right)\right]_{2}$ is stored as a solution or when solutions are heated, due to reaction with traces of oxygen.

Method B. A purple solution of $\left[\mathrm{U}\left(\mathrm{OBMes}_{2}\right)_{2}\left(\mu-\mathrm{OBMes}_{2}\right)\right]_{2}$ $(25 \mathrm{mg}, 0.012 \mathrm{mmol})$ in $\mathrm{C}_{6} \mathrm{D}_{6}(0.4 \mathrm{~mL})$ was prepared in situ in a Young's NMR tube. The solution was then degassed by three freeze pump thaw cycles and exposed to 1 bar pressure of $\mathrm{N}_{2} \mathrm{O}$. The mixture was agitated to give an immediate colour change to light brown. Formation of complex $\left[\mathrm{OU}\left(\mathrm{OBMes}_{2}\right)_{3}\right]_{n}$ was confirmed by NMR spectroscopy and elemental analysis.

${ }^{1} \mathrm{H}$ NMR $\left(500 \mathrm{MHz}, \mathrm{C}_{6} \mathrm{D}_{6}\right): \delta_{\mathrm{H}} 5.90$ (Ar-H Mes); $1.89\left(p-\mathrm{CH}_{3}\right.$ Mes); -0.52 (o-CH $\left.\mathrm{CH}_{3} \mathrm{Mes}\right)$.

${ }^{11} \mathrm{~B}$ NMR (160.46 MHz, $\left.\mathrm{C}_{6} \mathrm{D}_{6}\right): \delta_{\mathrm{B}} 89.29$ (OBMes).

${ }^{13} \mathrm{C}$ NMR $\left(126 \mathrm{MHz}, \mathrm{C}_{6} \mathrm{D}_{6}\right): \delta_{\mathrm{H}} 184.55$ (free CO); $166.10(o-\mathrm{C}$ Mes); 137.10 ( $p$-C Mes); 133.59 (C-B Mes); 126.94 (Ar-CH Mes); 21.29 ( $\left.p-\mathrm{CH}_{3} \mathrm{Mes}\right) ; 5.05$ ( $\left.o-\mathrm{CH}_{3} \mathrm{Mes}\right)$.

Elemental analysis: C $61.80 \%, \mathrm{H} 6.34 \%$ calculated. C $61.75 \%, \mathrm{H} 6.37 \%$ found.

FTIR $\left(\mathrm{cm}^{-1}\right)$ : 3617, 2728, 1721, 1608, 1552, 1280, 1228, 1175, 1152, 1081, 1029, 960, 928, 840, 745, 670.

$\left[\mathrm{U}\left(\mathrm{OBMes}_{2}\right)_{4}(\mathrm{OPy})_{2}\right]_{n}\left(4^{\mathrm{m}}\right)$

A Young's NMR tube was charged with $\left[\mathrm{U}\left(\mathrm{OBMes}_{2}\right)_{2}(\mu-\right.$ OBMes $\left.\left._{2}\right)\right]_{2}(25 \mathrm{mg}, 0.012 \mathrm{mmol}), \mathrm{C}_{5} \mathrm{H}_{5} \mathrm{NO}(5 \mathrm{mg}, 0.048 \mathrm{mmol}$, 4 eq.) and $\mathrm{C}_{6} \mathrm{D}_{6}(0.4 \mathrm{~mL})$. The reaction mixture turned dark brown immediately and was allowed to react for 72 hours, during which time dark orange crystals of $\left[\mathrm{U}\left(\mathrm{OBMes}_{2}\right)_{4}(\mathrm{Py}-\mathrm{O})_{2}\right]$ deposited on the reaction vessel walls. Yield: $19 \mathrm{mg}, 65 \%$.

${ }^{1} \mathrm{H}$ NMR $\left(500 \mathrm{MHz}, \mathrm{C}_{6} \mathrm{D}_{6}\right): \delta_{\mathrm{H}} 6.76(\mathrm{Ar}-\mathrm{H}$ Mes, $12 \mathrm{H}) ; 4.42$ (Py-O H, 6H); 2.31 (o- $\mathrm{CH}_{3}$ Mes, 36H); 2.16 ( $p$ - $\mathrm{CH}_{3}$ Mes, $\left.18 \mathrm{H}\right)$ 1.96 (Py-O H, 4H).

${ }^{11} \mathrm{~B}$ NMR $\left(160.46 \mathrm{MHz}, \mathrm{C}_{6} \mathrm{D}_{6}\right)$ : not observed in the window $+130--130$ ppm.

MS (APPI): $m / z=1223\left([\mathrm{M}]^{++}\left[\mathrm{U}\left(\mathrm{OBMes}_{2}\right)_{3}(\mathrm{Py}-\mathrm{O})_{2}\right]\right)$. $\mathrm{C}_{64} \mathrm{H}_{6} \mathrm{~B}_{3} \mathrm{~N}_{2} \mathrm{O}_{5} \mathrm{U}^{*+}[\mathrm{M}]^{++}$requires 1223.6541 , found 1223.6552 $(-1.1 \mathrm{ppm})$.

Dark orange crystals suitable for SCXRD analysis were grown from concentrated benzene solutions, however, the data are only of sufficient quality to discuss connectivity and not detailed metrics.

\section{$\left[\mathrm{U}\left(\mathrm{OBMes}_{2}\right)_{3}\left(\mathrm{OPPh}_{3}\right)_{2}\right]\left(5^{\mathrm{m}}\right.$ and $\left.6^{\mathrm{m}}\right)$}

$\left[\mathrm{U}\left(\mathrm{OBMes}_{2}\right)_{2}\left(\mu-\mathrm{OBMes}_{2}\right)\right]_{2}(25 \mathrm{mg}, 0.012 \mathrm{mmol})$ and $\mathrm{OPPh}_{3}$ (7 mg, $0.024 \mathrm{mmol}, 2 \mathrm{eq}$.) were placed in a Young's NMR tube. The tube's contents were dissolved in $\mathrm{C}_{6} \mathrm{D}_{6}(0.4 \mathrm{~mL}) .{ }^{1} \mathrm{H}$ NMR confirmed the formation of $\left[\mathrm{U}\left(\mathrm{OBMes}_{2}\right)_{3}\left(\mathrm{OPPh}_{3}\right)_{2}\right]\left(5^{\mathrm{m}}\right)$. Cocrystals of $5^{\mathbf{m}}$ and the side product $\left[\mathrm{U}\left(\mathrm{OBMes}_{2}\right)_{3}\left(\mathrm{~B}_{2} \mathrm{O}_{3} \mathrm{Mes}_{2}\right)\right]$ $\left(6^{\mathbf{m}}\right)$ suitable for X-ray diffraction studies were grown by slow diffusion of hexane into a concentrated benzene solution of [U(OBMes $\left.\left.)_{3}\right)_{3}\left(\mathrm{OPPh}_{3}\right)_{2}\right]$. Yield: $23 \mathrm{mg}, 60 \%$.

${ }^{1} \mathrm{H}$ NMR $\left(500 \mathrm{MHz}, \mathrm{C}_{6} \mathrm{D}_{6}\right): \delta_{\mathrm{H}} 6.90($ Ar-H Mes, $12 \mathrm{H}) ; 6.46$ $(p-\mathrm{Ph} \mathrm{H}, 6 \mathrm{H}) ; 5.92(o-\mathrm{Ph} \mathbf{H}, 12 \mathrm{H}) ; 3.64\left(o-\mathrm{CH}_{3} \mathrm{Mes}, 36 \mathrm{H}\right) ; 2.85$ $(m-\mathrm{Ph} \mathbf{H}, 12 \mathrm{H}) ; 1.87\left(p-\mathrm{CH}_{3}\right.$ Mes, $\left.18 \mathrm{H}\right)$.

${ }^{11} \mathrm{~B}$ NMR $\left(160.46 \mathrm{MHz}, \mathrm{C}_{6} \mathrm{D}_{6}\right)\left(5^{\mathbf{m}}\right): \delta_{\mathrm{B}}$ not observed in the window $+130--130 \mathrm{ppm}$.

${ }^{31} \mathrm{P}$ NMR $\left(202 \mathrm{MHz}, \mathrm{C}_{6} \mathrm{D}_{6}\right): \delta_{\mathrm{P}}-17.83\left(\mathrm{OPPh}_{3}\right)$.

$\mathrm{MS}$ (APPI): $m / z=1589\left([\mathrm{M}]^{++}\left[\mathrm{U}\left(\mathrm{OBMes}_{2}\right)_{3}\left(\mathrm{OPPh}_{3}\right)_{2}\right]\right)$ $\mathrm{C}_{90} \mathrm{H}_{96} \mathrm{~B}_{3} \mathrm{O}_{5} \mathrm{P}_{2} \mathrm{U}^{*+}[\mathrm{M}]^{\circ+}$ requires 1589.7520 , found 1589.7790 $(-27.0 \mathrm{ppm})$.

\section{$\left[\left\{\mathrm{U}\left(\mathrm{OBMes}_{2}\right)_{3}\right\}_{2}\left(\boldsymbol{\mu}-\eta^{2}: \eta^{2}-\mathbf{S}_{2}\right)_{2}\right]\left(7^{\mathrm{m}}\right)$}

To a magnetically stirred, dark purple solution of $\left[\mathrm{U}\left(\mathrm{OBMes}_{2}\right)_{2}\left(\mu-\mathrm{OBMes}_{2}\right)\right]_{2}(165 \mathrm{mg}, 0.08 \mathrm{mmol})$ in $2 \mathrm{~mL}$ of toluene in a $7 \mathrm{~cm}^{3}$ vial was added elemental sulfur $(10 \mathrm{mg}$, 
$0.04 \mathrm{mmol}, 0.5$ eq.) with stirring and the reaction was allowed to stir for 2 hours. Dark red crystals of $\left[\left\{\left(\mathrm{OBMes}_{2}\right)_{3} U\right\}_{2}\left(\mu-\eta^{2}: \eta^{2}-\right.\right.$ $\left.\mathrm{S}_{2}\right)_{2}$ ] suitable for X-ray diffraction can be obtained from storage of a concentrated benzene solution at room temperature. Yield: $32 \mathrm{mg}, 18 \%$.

${ }^{1} \mathrm{H}$ NMR (500 MHz, $\mathrm{C}_{6} \mathrm{D}_{6}$ ): $\delta_{\mathrm{H}} 6.88$ (Ar-H Mes, 24H); 2.38 ( $p$ - $\mathrm{CH}_{3}$ Mes, 36H); 2.23 (o- $\mathrm{CH}_{3}$ Mes, 72H).

${ }^{11} \mathrm{~B}$ NMR (160.46 MHz, $\left.\mathrm{C}_{6} \mathrm{D}_{6}\right)$ : not observed in the window +130--130 ppm. MS (APPI): $m / z=1097\left([\mathrm{M}]^{\circ+}\right.$. $\left.\left[\mathrm{U}\left(\mathrm{OBMes}_{2}\right)_{3}\left(\mu-\mathrm{S}_{2}\right)\right]\right) \mathrm{C}_{54} \mathrm{H}_{66} \mathrm{~B}_{3} \mathrm{O}_{3} \mathrm{~S}_{2} \mathrm{U}^{\bullet+}[\mathrm{M}]^{\bullet+}$ requires 1097.5240, found 1097.5259 (-1.9 $\mathrm{ppm})$.

\section{$\left[\mathrm{U}\left(\eta^{2}-\mathrm{DCC}\right)\left(\mathrm{OBMes}_{2}\right)_{3}\right]\left(8^{\mathrm{m}}\right)$}

A solution of $N, N^{\prime}$-dicyclohexylcarbodiimide [(DCC $=\eta^{2}-\mathrm{N}(\mathrm{Cy}) \mathrm{C}$ $\left.(=\mathrm{NCy}) \mathrm{N}(\mathrm{Cy})] ; \mathrm{Cy}=\mathrm{C}_{6} \mathrm{H}_{11}\right)(10 \mathrm{mg}, 0.048 \mathrm{mmol}, 2$ eq. $)$ in benzene $(1 \mathrm{~mL})$ was added dropwise to a stirring benzene solution of $\left[\mathrm{U}\left(\mathrm{OBMes}_{2}\right)_{2}\left(\mu-\mathrm{OBMes}_{2}\right)\right]_{2}(50 \mathrm{mg}, 0.024 \mathrm{mmol})$ in a $7 \mathrm{~cm}^{3}$ vial. The solution turned green immediately and was allowed to stir for 18 hours. The solution was then filtered and evaporated to dryness. ${ }^{1} \mathrm{H}$ NMR spectroscopy confirmed the formation of the title compound. Yield: $22 \mathrm{mg}, 69 \%$.

${ }^{1} \mathrm{H}$ NMR $\left(500 \mathrm{MHz}, \mathrm{C}_{6} \mathrm{D}_{6}\right): \delta_{\mathrm{H}} 58.36(\mathrm{Cy} \mathrm{H}, 1 \mathrm{H}) ; 43.14(\mathrm{Cy} \mathbf{H}$, 1H); 28.62 (Сy H, 3H); 13.73 (Сy H, 2H); 12.48 (Су H, 1H); 11.15 (Су H, 2H); 9.66 (Су H, 1H); 9.06 (Су H, 3H); 7.64 (Су H, 2H); 7.32 (Сy H, 1H); 6.75 (Ar-H Mes, 12H); 6.48 (Су H, 2H);

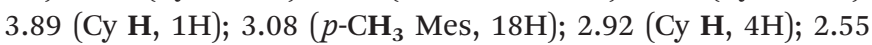
(Су Н, 1H); 2.16 (Су Н, 1H); 1.76 (Су H, 1H); -4.75 (Су Н, 1H); -6.63 (Сy H, 1H); -10.39 (o-CH $\mathbf{C H}_{3}$ Mes, 36H); -10.62 (Су H, 4H).

MS (APPI): $m / z=1338\left([\mathrm{M}+\mathrm{H}]\left(\mathrm{OBMes}_{2}\right)_{3} \mathrm{U}\left[\eta^{2}-\mathrm{N}\left(\mathrm{C}_{6} \mathrm{H}_{11}\right) \mathrm{C}\right.\right.$ $\left.\left.\left(=\mathrm{NC}_{6} \mathrm{H}_{11}\right) \mathrm{N}-\left(\mathrm{C}_{6} \mathrm{H}_{11}\right)\right]\right) \quad \mathrm{C}_{73} \mathrm{H}_{100} \mathrm{~B}_{3} \mathrm{~N}_{3} \mathrm{O}_{3} \mathrm{U}^{+}[\mathrm{M}+\mathrm{H}]^{+}$requires 1337.8552, found 1337.8577 (-2.5 ppm).

\section{$\left[\left\{\mathrm{U}\left(\mathrm{OBTrip}_{2}\right)_{3}\right\}_{2}\left(\boldsymbol{\mu}-\mathrm{CO}_{3}\right)\right]\left(9^{\mathrm{t}}\right)$}

A purple-brown solution of $\left[\mathrm{U}\left(\mathrm{OBTripp}_{2}\right)_{3}\right]_{2} \quad(75 \mathrm{mg}$, $0.048 \mathrm{mmol}, 1$ eq.) in $\mathrm{C}_{5} \mathrm{H}_{10}$ prepared in situ in a Young's NMR tube was degassed by three freeze pump thaw cycles and placed under a 1 bar pressure of $\mathrm{CO}_{2}$ at room temperature. The mixture was agitated to give an immediate colour change to light green-brown. The reaction mixture was allowed to stand overnight at room temperature. Crystalline $\left[\mathrm{U}\left(\mathrm{OBTrip}_{2}\right)_{3}\right]_{2}\left(\mu-\mathrm{CO}_{3}\right)$ was obtained by slow diffusion of hexanes into the reaction mixture. Yield: $4 \mathrm{mg}, 2 \%$. Due to the extremely low yield of isolated material, no further characterising data were obtainable.

\section{$\left[\mathrm{U}\left(\mathrm{OBMes}_{2}\right) \mathbf{N}_{3}\right]\left(\mathbf{1 1}^{\mathrm{m}}\right)$}

Method A: UIN" ${ }_{3}(225 \mathrm{mg})$ and $\mathrm{KOBMes}_{2}(100 \mathrm{mg})$ were placed into a Schlenk flask with a stirrer bar. Toluene $(15 \mathrm{~mL})$ was introduced into the flask and the contents were stirred overnight. The solution was then cannula filtered and the solvent removed. The resulting residue was washed with cold hexanes $(2 \times 5 \mathrm{~mL})$ to yield the title compound $\mathbf{1 1}^{\mathbf{m}}(205 \mathrm{mg}, 78 \%)$.

Method B: $\left(\mathrm{N}^{\prime \prime}\right)_{2} \mathrm{U}\left\{\mathrm{\kappa}^{2}-(\mathrm{N}, \mathrm{C})-\mathrm{N}\left(\mathrm{SiMe}_{3}\right) \mathrm{SiMe}_{2} \mathrm{CH}_{2}\right\}(10 \mathrm{mg})$ and dimesitylborinic acid $(3.5 \mathrm{mg})$ were placed in an NMR tube and dissolved in $\mathrm{C}_{6} \mathrm{D}_{6}(0.5 \mathrm{~mL}) .{ }^{1} \mathrm{H}$ NMR showed that quantitative formation of $\mathrm{U}\left(\mathrm{OBMes}_{2}\right) \mathrm{N}_{3}$ had occurred. Crystals suit- able for X-ray diffraction studies were grown by slow evaporation of a toluene solution of $\mathrm{U}\left(\mathrm{OBMes}_{2}\right) \mathrm{N}_{3}{ }_{3}$. Local code P18053_tri.

${ }^{1} \mathrm{H}$ NMR $\left(\mathrm{C}_{6} \mathrm{D}_{6}\right): \delta_{\mathrm{H}} 7.52(\mathrm{~s}, 4 \mathrm{H}), 4.89(\mathrm{~s}, 12 \mathrm{H}), 2.48(\mathrm{~s}, 6 \mathrm{H})$, $-6.68(\mathrm{~s}, 54 \mathrm{H})$; anal. Calc for $\mathrm{C}_{36} \mathrm{H}_{76} \mathrm{~B}_{1} \mathrm{~N}_{3} \mathrm{O}_{1} \mathrm{Si}_{6} \mathrm{U}_{1}$ : C, $52.58 \mathrm{H}$, $8.01 \mathrm{~N}, 3.41 \%$. Found: C, $52.39 \mathrm{H}, 7.34 \mathrm{~N}, 3.53 \%$; EI-MS $(\mathrm{m} / \mathrm{z})$ : $823.2\left[\mathrm{M}-\mathrm{N}^{\prime \prime}\right]^{+}$.

\section{$\left[\mathrm{U}\left(\mathrm{OBTrip}_{2}\right) \mathbf{N}_{3}{ }_{3}\right]\left(\mathbf{1 1}^{\mathrm{t}}\right)$}

Complex U(OBTrip 2$) \mathrm{N}_{3}{ }_{3} \mathbf{1 1}^{\mathbf{t}}$ was also isolated as a side product in $5 \%$ yield from the synthesis of $\mathbf{1}^{\mathbf{t}} \cdot \mathbf{O E t}_{\mathbf{2}}$ as a brown precipitate, and washed with $\mathrm{Et}_{2} \mathrm{O}(0.5 \mathrm{~mL} \times 3)$ in low yield $(46 \mathrm{mg}$, $0.04 \mathrm{mmol}, 5 \%$ yield based on $\mathrm{HOBTrip}_{2}$ ). Colourless crystals of $\mathbf{1 1}^{\mathbf{t}}$ suitable for X-ray diffraction analysis were obtained from concentrated benzene solution upon standing at room temperature. Local code P18083.

${ }^{1} \mathrm{H}$ NMR (500 MHz, $\left.\mathrm{C}_{6} \mathrm{D}_{6}\right): \delta 41.93(\mathrm{~s}, 1 \mathrm{H}, \mathrm{Ar}-\mathrm{H}), 16.81(\mathrm{~s}$, $1 \mathrm{H}, \mathrm{Ar}-\mathrm{H}$ ), 11.70 (s, 2H, Ar-H), 10.47 (s, 1H, Ar-H), 9.29 (s, 2H, $\mathrm{CH}), 8.01$ (s, 1H, CH), 7.48 (s, 2H, CH), 3.25 (s, 12H, $\left.\mathrm{CH}_{3}\right), 1.98$ $\left(\mathrm{s}, 3 \mathrm{H}, \mathrm{CH}_{3}\right), 1.21\left(\mathrm{~s}, 3 \mathrm{H}, \mathrm{CH}_{3}\right), 1.10\left(\mathrm{~s}, 3 \mathrm{H}, \mathrm{CH}_{3}\right), 0.52(\mathrm{~s}, 3 \mathrm{H}$, $\left.\mathrm{CH}_{3}\right), 1.48\left(\mathrm{~s}, 9 \mathrm{H}, \mathrm{CH}_{3}\right),-4.63\left(\mathrm{~s}, 3 \mathrm{H}, \mathrm{CH}_{3}\right),-7.36(\mathrm{~s}, 12 \mathrm{H}$, $\left.\mathrm{CH}_{3}\right),-10.03\left(\mathrm{~s}, 24 \mathrm{H}, \mathrm{CH}_{3}\right),-14.56\left(\mathrm{~s}, 18 \mathrm{H}, \mathrm{CH}_{3}\right)$. There is restricted rotation of the $\mathrm{CH}_{3}$ groups at room temperature on the ${ }^{1} \mathrm{H}$ NMR timescale. ${ }^{11} \mathrm{~B}$ NMR (160.46 MHz, $\left.\mathrm{C}_{6} \mathrm{D}_{6}\right): 109.74$ (O-B-Ar).

\section{Conflicts of interest}

There are no conflicts to declare.

\section{Acknowledgements}

We thank the University of Edinburgh and the EPSRC for funding through $\mathrm{EP} / \mathrm{H} 004823 / 1$ and EP/M010554/1, EP/ J018139/1 and the UK Catalysis Hub EP/K014714/1. This project has also received funding from the European Research Council (ERC) under the European Union's Horizon 2020 research and innovation programme (grant agreement No 740311). The support provided by China Scholarship Council (CSC) during a visit of D. Y. to the University of Edinburgh is acknowledged. We would also like to thank Dr Colin Logan Mackay of the University of Edinburgh for mass spectrometry and the University of Edinburgh SIRCAMS facility for use of the FTICRMS.

\section{References}

1 P. L. Arnold, Z. R. Turner, R. M. Bellabarba and R. P. Tooze, Chem. Sci., 2011, 2, 77-79.

2 S. M. Mansell, N. Kaltsoyannis and P. L. Arnold, J. Am. Chem. Soc., 2011, 133, 9036-9051.

3 S. M. Mansell, J. H. Farnaby, A. I. Germeroth and P. L. Arnold, Organometallics, 2013, 32, 4214-4222. 
4 M. Falcone, L. Chatelain, R. Scopelliti, I. Živković and M. Mazzanti, Nature, 2017, 547, 332.

5 V. Mougel, C. Camp, J. Pécaut, C. Copéret, L. Maron, C. E. Kefalidis and M. Mazzanti, Angew. Chem., Int. Ed., 2012, 51, 12280-12284.

6 P. L. Arnold, S. M. Mansell, L. Maron and D. McKay, Nat. Chem., 2012, 4, 668-674.

7 S. C. Cole, M. P. Coles and P. B. Hitchcock, J. Chem. Soc., Dalton Trans., 2002, 4168-4174.

8 M. P. Coles, Coord. Chem. Rev., 2016, 323, 52-59.

9 O. J. Cooper, J. McMaster, W. Lewis, A. J. Blake and S. T. Liddle, Dalton Trans., 2010, 39, 5074-5076.

10 D. M. King, W. Lewis and S. T. Liddle, Inorg. Chim. Acta, 2012, 380, 167-173.

11 I. Korobkov, S. Gorelsky and S. Gambarotta, J. Am. Chem. Soc., 2009, 131, 10406-10420.

12 C. R. Groom, I. J. Bruno, M. P. Lightfoot and S. C. Ward, Acta Crystallogr., Sect. B: Struct. Sci., Cryst. Eng. Mater., 2016, 72, 171-179.

13 A.-C. Schmidt, F. W. Heinemann, W. W. Lukens and K. Meyer, J. Am. Chem. Soc., 2014, 136, 11980-11993.

14 M. J. Monreal, R. K. Thomson, T. Cantat, N. E. Travia, B. L. Scott and J. L. Kiplinger, Organometallics, 2011, 30, 2031-2038.

15 J. A. L. Wells, M. L. Seymour, M. Suvova and P. L. Arnold, Dalton Trans., 2016, 45, 16026-16032.

16 J. A. L. Wells, PhD thesis, University of Edinburgh, 2018.

17 A. Zalkin, J. G. Brennan and R. A. Andersen, Acta Crystallogr., Sect. C: Cryst. Struct. Commun., 1988, 44, 1553-1554.

18 C. J. Burns, W. H. Smith, J. C. Huffman and A. P. Sattelberger, J. Am. Chem. Soc., 1990, 112, 3237-3239.

19 C. Camp, J. Pécaut and M. Mazzanti, J. Am. Chem. Soc., 2013, 135, 12101-12111.

20 H. J. Wasserman, D. C. Moody and R. R. Ryan, J. Chem. Soc., Chem. Commun., 1984, 532-533.

21 D. S. J. Arney and C. J. Burns, J. Am. Chem. Soc., 1995, 117, 9448-9460.

22 D. S. J. Arney and C. J. Burns, J. Am. Chem. Soc., 1993, 115, 9840-9841.

23 O. Cooper, C. Camp, J. Pécaut, C. E. Kefalidis, L. Maron, S. Gambarelli and M. Mazzanti, J. Am. Chem. Soc., 2014, 136, 6716-6723.

24 S. J. Kraft, J. Walensky, P. E. Fanwick, M. B. Hall and S. C. Bart, Inorg. Chem., 2010, 49, 7620-7622.

25 L. R. Avens, D. M. Barnhart, C. J. Burns, S. D. McKee and W. H. Smith, Inorg. Chem., 1994, 33, 4245-4254.

26 A. J. Lewis, U. J. Williams, J. M. Kikkawa, P. J. Carroll and E. J. Schelter, Inorg. Chem., 2012, 51, 37-39.

27 N. L. Bell, P. L. Arnold and J. B. Love, Dalton Trans., 2016, 45, 15902-15909.

28 J. A. Pool, B. L. Scott and J. L. Kiplinger, J. Am. Chem. Soc., 2005, 127, 1338-1339.

29 N. A. Siladke, J. LeDuc, J. W. Ziller and W. J. Evans, Chem. Eur. J., 2012, 18, 14820-14827.

30 J.-C. Berthet, M. Nierlich and M. Ephritikhine, Dalton Trans., 2004, 2814-2821.
31 S. Kannan, M. A. Moody, C. L. Barnes and P. B. Duval, Inorg. Chem., 2006, 45, 9206-9212.

32 J. J. Kiernicki, J. S. Harwood, P. E. Fanwick and S. C. Bart, Dalton Trans., 2016, 45, 3111-3119.

33 T. W. Hayton, J. M. Boncella, B. L. Scott, E. R. Batista and P. J. Hay, J. Am. Chem. Soc., 2006, 128, 10549-10559.

34 R. E. Jilek, L. P. Spencer, R. A. Lewis, B. L. Scott, T. W. Hayton and J. M. Boncella, J. Am. Chem. Soc., 2012, 134, 9876-9878.

35 R. E. Jilek, N. C. Tomson, B. L. Scott and J. M. Boncella, Inorg. Chim. Acta, 2014, 422, 78-85.

36 J.-C. Berthet, M. Nierlich and M. Ephritikhine, Polyhedron, 2003, 22, 3475-3482.

37 N. A. Ayoub, A. R. Browne, B. L. Anderson and T. G. Gray, Dalton Trans., 2016, 45, 3820-3830.

38 Z. Yang, X. Ma, R. B. Oswald, H. W. Roesky and M. Noltemeyer, J. Am. Chem. Soc., 2006, 128, 12406-12407.

39 X. Ma, Z. Yang, X. Wang, H. W. Roesky, F. Wu and H. Zhu, Inorg: Chem., 2011, 50, 2010-2014.

40 Z. Yang, P. Hao, Z. Liu, X. Ma, H. W. Roesky and J. Li, J. Organomet. Chem., 2014, 751, 788-791.

41 M. Kořenková, B. Mairychová, R. Jambor, Z. Růžičková and L. Dostál, Inorg. Chem. Commun., 2014, 47, 128-130.

42 M. Kořenková, M. Erben, R. Jambor, A. Růžička and L. Dostál, J. Organomet. Chem., 2014, 772-773, 287-291.

43 B. Mairychová, T. Svoboda, P. Štěpnička, A. Růžička, R. W. A. Havenith, M. Alonso, F. D. Proft, R. Jambor and L. Dostál, Inorg. Chem., 2013, 52, 1424-1431.

44 B. Mairychová, P. Štěpnička, A. Rủžička, L. Dostál and R. Jambor, Organometallics, 2014, 33, 3021-3029.

45 B. Mairychová, I. V. Kityk, A. Maciag, F. Bureš, M. Klikar, A. Růžička, L. Dostál and R. Jambor, Inorg. Chem., 2016, 55, 1587-1594.

46 L. Dostál, R. Jambor, A. Růžička, R. Jirásko, A. Lyčka, J. Beckmann and S. Ketkov, Inorg. Chem., 2015, 54, 6010-6019.

47 M. Kořenková, B. Mairychová, A. Růžička, R. Jambor and L. Dostál, Dalton Trans., 2014, 43, 7096-7108.

48 U. Bossek, H. Hummel, T. Weyhermüller, K. Wieghardt, S. Russell, L. van der Wolf and U. Kolb, Angew. Chem., Int. Ed., 1996, 35, 1552-1554.

49 A. R. Browne, N. Deligonul, B. L. Anderson, M. Zeller, A. D. Hunter and T. G. Gray, Chem. Commun., 2015, 51, 15800-15803.

50 I. Pantcheva and K. Osakada, Organometallics, 2006, 25, 1735-1741.

51 H. Yin, A. J. Lewis, U. J. Williams, P. J. Carroll and E. J. Schelter, Chem. Sci., 2013, 4, 798-805.

52 E. Barnea, T. Andrea, M. Kapon and M. S. Eisen, J. Am. Chem. Soc., 2004, 126, 5066-5067.

53 R. K. Das, E. Barnea, T. Andrea, M. Kapon, N. Fridman, M. Botoshansky and M. S. Eisen, Organometallics, 2015, 34, 742-752.

54 K. I. M. Ingram, N. Kaltsoyannis, A. J. Gaunt and M. P. Neu, J. Alloys Compd., 2007, 444-445, 369-375.

55 H. H. Dam, D. N. Reinhoudt and W. Verboom, Chem. Soc. Rev., 2007, 36, 367-377. 
56 S. R. Daly, J. M. Keith, E. R. Batista, K. S. Boland, D. L. Clark, S. A. Kozimor and R. L. Martin, J. Am. Chem. Soc., 2012, 134, 14408-14422.

57 D. E. Smiles, G. Wu, P. Hrobárik and T. W. Hayton, J. Am. Chem. Soc., 2016, 138, 814-825.

58 J. K. Pagano, D. S. J. Arney, B. L. Scott, D. E. Morris, J. L. Kiplinger and C. J. Burns, Dalton Trans., 2019, 48, 50-57.

59 S. M. Franke, F. W. Heinemann and K. Meyer, Chem. Sci., 2014, 5, 942-950.

60 B. M. Gardner, D. M. King, F. Tuna, A. J. Wooles, N. F. Chilton and S. T. Liddle, Chem. Sci., 2017, 8, 62076217.

61 D. E. Smiles, G. Wu and T. W. Hayton, New J. Chem., 2015, 39, 7563-7566.

62 D. L. Perry, A. Zalkin, H. Ruben and D. H. Templeton, Inorg. Chem., 1982, 21, 237-240.

63 D. J. Grant, Z. Weng, L. J. Jouffret, P. C. Burns and L. Gagliardi, Inorg. Chem., 2012, 51, 7801-7809.

64 J. L. Brown, G. Wu and T. W. Hayton, Organometallics, 2013, 32, 1193-1198.

65 E. M. Matson, M. D. Goshert, J. J. Kiernicki, B. S. Newell, P. E. Fanwick, M. P. Shores, J. R. Walensky and S. C. Bart, Chem. - Eur. J., 2013, 19, 16176-16180.

66 A. C. Sutorik and M. G. Kanatzidis, Polyhedron, 1997, 16, 3921-3927.

67 J.-E. Kwak, D. L. Gray, H. Yun and J. A. Ibers, Acta Crystallogr., Sect. E: Struct. Rep. Online, 2006, 62, i86-i87.

68 C. Camp, M. A. Antunes, G. García, I. Ciofini, I. C. Santos, J. Pécaut, M. Almeida, J. Marçalo and M. Mazzanti, Chem. Sci., 2014, 5, 841-846.

69 A. Terzis and R. Rivest, Inorg. Chem., 1973, 12, 2132-2136.

70 R. C. Elder and M. Trkula, Inorg. Chem., 1977, 16, 10481051.

71 J. T. York, E. C. Brown and W. B. Tolman, Angew. Chem., Int. Ed., 2005, 44, 7745-7748.
72 S. Yao, C. Milsmann, E. Bill, K. Wieghardt and M. Driess, J. Am. Chem. Soc., 2008, 130, 13536-13537.

73 W. J. Evans, J. R. Walensky, J. W. Ziller and A. L. Rheingold, Organometallics, 2009, 28, 3350-3357.

74 W. J. Evans, M. K. Takase, J. W. Ziller and A. L. Rheingold, Organometallics, 2009, 28, 5802-5808.

75 M. K. Takase, N. A. Siladke, J. W. Ziller and W. J. Evans, Organometallics, 2011, 30, 458-465.

76 O. J. Cooper, D. P. Mills, W. Lewis, A. J. Blake and S. T. Liddle, Dalton Trans., 2014, 43, 14275-14283.

77 M. A. Boreen, B. F. Parker, T. D. Lohrey and J. Arnold, J. Am. Chem. Soc., 2016, 138, 15865-15868.

78 W. J. Evans, J. R. Walensky and J. W. Ziller, Organometallics, 2010, 29, 101-107.

79 W. J. Evans, J. R. Walensky and J. W. Ziller, Inorg. Chem., 2010, 49, 1743-1749.

80 N. A. Siladke, J. W. Ziller and W. J. Evans, J. Am. Chem. Soc., 2011, 133, 3507-3516.

81 L. Zhang, C. Zhang, G. Hou, G. Zi and M. D. Walter, Organometallics, 2017, 36, 1179-1187.

82 L. Zhang, G. Hou, G. Zi, W. Ding and M. D. Walter, J. Am. Chem. Soc., 2016, 138, 5130-5142.

83 L. Zhang, B. Fang, G. Hou, G. Zi, W. Ding and M. D. Walter, Organometallics, 2017, 36, 898-910.

84 G. Zi, Chem. Commun., 2018, 54, 7412-7430.

85 O. T. Summerscales, A. S. P. Frey, F. G. N. Cloke and P. B. Hitchcock, Chem. Commun., 2008, 198-200.

86 C. J. Inman, A. S. P. Frey, A. F. R. Kilpatrick, F. G. N. Cloke and S. M. Roe, Organometallics, 2017, 36, 4539-4545.

87 N. Tsoureas, L. Castro, A. F. R. Kilpatrick, F. G. N. Cloke and L. Maron, Chem. Sci., 2014, 5, 3777-3788.

88 L. Castro, O. P. Lam, S. C. Bart, K. Meyer and L. Maron, Organometallics, 2010, 29, 5504-5510.

89 A. J. Lewis, U. J. Williams, P. J. Carroll and E. J. Schelter, Inorg. Chem., 2013, 52, 7326-7328. 